\title{
Securities Transaction Tax and Market Quality - The Case of France
}

\author{
Martin Haferkorn and Kai Zimmermann \\ Chair of e-Finance \\ Goethe University Frankfurt
}

\begin{abstract}
The French Securities Transaction Tax (STT) implementation on August $1^{\text {st }}, 2012$, is considered a landmark development within securities markets regulation. However, until today the controversy about possible drawbacks and applicability has not reached a conclusion and consequences for market quality are yet to be thoroughly assessed. In this light a rigorous evaluation on the STT's effect on market quality is highly desirable and would provide guidance for academics, regulators and practitioners alike. On this basis, we provide evidence that trading activity declines by approximately $16 \%$ after the introduction of the STT. Even though the French proposal exempts liquidity providing activities, we find increased spread levels and a strong decline in top order book depth resulting in additional transaction costs for market participants beside the tax. Most alerting, as the STT affects trading on all French listing venues, we find this deterioration in market quality threatening inter-market information transmission by impairing price coordination among the European fragmented markets.
\end{abstract}

\section{Introduction}

The concept of the securities transaction tax (STT) has been one of the most controversially discussed topics in financial markets regulation during the last four decades. Politicians argue that this tax would dampen speculative trading activity leading to increased financial market integrity (Summers \& Summers, 1989) (Stiglitz, 1989). Contrary, opponents lay out that a STT would not only impair financial markets but also unnecessarily burden the economy by biasing investor's capital allocation (Matheson, 2011) (Habermeier \& Kirilenko, 2001). Although theoretical research is considered widespread and advanced along with some empirical studies, no common understanding on how an STT affects market quality could yet be established. In particular, detailed results of the effects on market quality are very limited. These scarce empirical results are further challenged in their applicability in todays market settings as conditions in recent years have changed drastically. In Europe, the ongoing fragmentation process induced by the Markets in Financial Instruments Directive (MiFID) catalyzed competition among trading venues, new technologies (e.g. high frequency trading (HFT) as well as smart order routing) and different pricing regimes like maker-taker pricing added even more layers of complexity. In the light of a still ongoing controversy, opposed research results and the ongoing plans for a STT in many European countries, research is not only appealing but 
also highly crucial in providing guidance for regulators in particular and practitioners and academics alike.

In 2012, France decided to introduce a STT providing a very suitable and very recent case to draw empirical conclusions on this important matter. To follow the call of Schwert and Seguin (1993) we provide a detailed evidence on market quality by analyzing changes in trading activity as well as market quality parameters. Despite from adding further empirical evidence on the important quality matter of volatility and trading volumes we mainly concentrate on order book liquidity changes. We thereby seek to achieve a comprehensive overview by combining the evaluation of various dimensions of single-market quality parameters, e.g. price volatility and order book liquidity, together with an analysis of the fragmented market characteristic of the European trading system. We are the first to provide an in-depth insight into the structure of the order book, which puts us apart from previous work that focused only on liquidity aggregates (Pomeranets \& Weaver, 2012) (Chou \& Wang, 2005). This allows us to draw further conclusions on all dimensions of liquidity and therefore the effect on respective trader groups. We find trade executions (traded volumes) declining by on average 16\% (7\%) within 2 months after the adaption which is in line with previous studies like Pomeranets and Weaver (2012). By focusing on order book liquidity, we find a decline in order book depth nearly instantanious after the introduction of the STT followed by a widening of the relative spread levels although professional liquidity provision is not taxed. Most interestingly, high quality order book volume at the order book's top levels declines nearly by the same amount as volumes within the lower order book section, leading to additionally elevated implicit transaction costs next to the explicit tax fee. Market volatility levels remain unchanged in the long- as well as in the short-run and therefore give no indication if the lost order volume and trading activity was of distinct disorienting nature, as argued by Summers and Summers (1989) and Stiglitz (1989). In the light of the highly fragmented nature of today's Europe market landscape, we add another dimension of market quality analysis. Information transmission between dispersed markets is a major characteristic for price coordination ensuring price homogeneity and investment confidence (Hasbrouck, 1995). By investigating information transmission between two taxed markets before and after the STT, we give a preliminary insight how price dispersion is affected by the STT. We find price homogeneity as well as coordination between venues significantly deteriorated while simultaneously exogenous shocks to the long-term price equilibrium are reverted more slowly than before the tax.

Our article is structured as follows: In the first section we will present the current state of research indicating a short-coming for empirical evidence, especially within the investigation on market quality and liquidity. We then provide a systematic insight on the French STT outlining relevant characteristics. As especially liquidity providing strategies are excluded from being taxed, it is highly recommended to give insight into order book changes. In the research design section we exhibit our dataset along with our methodology. The results related to market quality and inter-market information transmission are given in the next two sections. Concluding remarks and outlook are given in the last section.

\section{Literature Review}

The concept of the transaction tax was first raised by James Tobin in 1978. He argued that a transaction tax would prevent speculation in the foreign exchange market which, as he argues, is burdening the economy by "throwing sand in the wheels of our 
excessively efficient international money markets" (Tobin, 1978). While Tobin intended to tax foreign exchange trades only, the concept was quickly adapted to other financial markets by regulators and researchers alike. Along with the adaption of the STT to other financial markets academia questioned if a STT would alter trading behavior and subsequently market conditions itself. Since then, academia tries to give evidence on answering this fundamental question on a theoretical and empirical basis. These current results are outlined in the next two sub sections.

\section{Theoretical Literature}

Debate. Summers and Summers (1989) pose the question of the feasibility and desirability of a STT. The feasibility of the tax is seen to be uncritical as it was implemented in Japan and the United Kingdom before. In the case of the desirability they conclude that the STT would free capital used for speculation which would be more sustainable in other business sectors. This effect would economically outweigh the costs of the removed securities market liquidity. The same results are obtained by Stiglitz (1989), he argues that a STT does not harm the function of a financial market if the volatility does not increase. In fact he further emphasizes that volatility would decline and relative spreads would not necessarily be widened. Due to the absence of noise traders he predicts that liquidity might even improve. Schwert and Seguin (1993) argue that a STT has not more negative externalities than positive ones. However, they note that no tax proposal aimed at the market for treasury bills. This leads them to the conclusion that legislators and regulators are aware of potential negative effects for the affected securities. Contrary, Matheson (2011) believes that a STT would be more harmful than helpful. He predicts that the short-run security values and short-term trading volumes would decline, resulting firstly in smaller profits for financial firms which will be compensated by higher levies for their costumers. Ultimately, the capital supply to corporations and therefore the economy will be limited impeding overall economy development. Spahn (1995) also denies the viability of a transaction tax in foreign exchange trading as a tax would impair the financial market and create liquidity problems. Habermeier and Kirilenko (2001) strongly oppose the introduction of a STT. They argue that the STT would have the similar effects as capital controls, i.e. higher volatility, less trading activity and liquidity. These factors would lead to a lower information efficiency.

Simulation. Demary (2011) dissects the effects of a STT on the basis of an agentbased simulation modeled with different trader types. He finds a decline in volatility if fundamental traders are more aggressive or chartists are less aggressive. He states further, that volatility rises if the risk aversion of traders ascends. Also with different traders types but in a two market-setting Mannaro, Marchesi, and Setzu (2008) assessed the STT. They find an increase of volatility in a single-market setting when chartists are present. Within a two-markets setting, where only one market is obliged to a STT, they find volumes on the taxed market declining while volatility simultaneously increases. On the same basis -also a two-markets setting- Hanke, Huber, Kirchler, and Sutter (2010) analyze the effect of a STT, and report in line with Mannaro et al. (2008) a decline of the volume on the taxed market which is caused by a shift towards the untaxed one. They conclude that changes on volatility depend on availability of tax heavens and the market size, however, a decrease in short-term speculation could be observed on the taxed market as well. In a recent paper, Pellizzari and Westerhoff (2009) study the effectiveness of a STT under different market designs. They emphasize that on a quote driven market a STT does not stabilize market dynamics and traders retreat resulting in 
lower volumes and liquidity. Thus, the individual price impact of an order increases. In the regard of the dealer market they indicate that the STT stabilizes market dynamics and, as liquidity is externally provided, it is not negatively affected. However, they note, that in a dealer market some traders may retreat accompanied by a decline in volatility.

Model. Dupont and Lee (2007) analyze the effects of a STT on depth and spread levels on a dealer market with a static model. They find that in times of low (high) information asymmetry the tax is incorporated in the spread together with small (high) surplus whilst the depth can increase (decrease). This could lead to a market closure if the liquidity providing market participants quit quoting. A worsening effect on liquidity is also reported by Subrahmanyam (1998). However, he observes on the basis of a dynamic model that a STT could give traders an incentive to acquire long-term information which would increase the long term price informativeness and therefore compensate negative effects in the long-run. Kupiec (1996) poses the question how the STT would affect stock volatility and securities prices within a general equilibrium model. He finds that volatility may exhibit a modest decline and security prices would decline more than the tax income would compensate. However, he concludes that the overall effect of an increase of the STT is positive. On the basis of a similar microeconomic equilibrium model, Palley (1999) studies the effects of a STT. Even though a STT could hamper trading of fundamental investors due to tax saving reasons it could contain the activity of noise traders which may be beneficial for market quality. The case of noise traders if a STT is enforced is further refined by Song and Zhang (2005). They imply, on the basis of their equilibrium model, that a low (high) share of noise traders and low (high) pre-STT volatility result in a decline (increase) in volatility.

\section{Empirical Literature}

While theoretical research focuses on argumentation and modeling of different trader groups and their reaction to a STT, empirical research analyzes well-known market quality parameters. In particular interest are parameters which are subject to research in theoretical studies (previous section), i.e. volatility (e.g. standard deviation of prices), liquidity (e.g. relative spread, Amihud liquidity measure) and trading activity (trading volume). As STTs are not widespread enough to draw general conclusions, research further utilizes the rise of explicit transaction costs as proxy for an introduction of a STT. Researchers argue that a higher cost base for market participants has the same effect on market quality as the introduction of a STT. However someone might question if a rise in transaction costs is comparable to factors like tax deductibility which might result in different behavior of market participants.

Volatility. Umlauf (1993) is among the first who gives evidence that volatility increases with the introduction of the Swedish STT. An increase of volatility caused by an introduction of a STT is further observed by Baltagi, Li, and Li (2006) in China and Sinha and Mathur (2012) in India. Pomeranets and Weaver (2012) observe a positive effect on volatility after a tax increase as well as a negative effect on volatility after the decrease of the New York State STT. In a longitudinal study across 23 countries Roll (1989) finds an insignificant increase in volatility accompanied with the STT. Phylaktis and Aristidou (2007) show an empirically increase in volatility during times of rising prices (bullish period) within the Greek securities markets but no significant effect on volatility in all other market periods. The same results -no effect on volatility- are also shared by $\mathrm{Hu}$ (1998) who analyzed the introduction of the STT in four Asian countries, 
likewise Saporta and Kan (1997) who researched on the matter of the stamp duty in the UK. This result is also backed up by Chou and Wang (2005) who observed no effect on volatility after a decrease in the transaction tax on future markets in Taiwan.

Green, Maggioni, and Murinde (2000) split volatility into market-volatility and fundamental-volatility. They find that with a rise in transaction costs fundamentalvolatility decreases and market-volatility increases. An increase of volatility caused by rising transaction costs is further observed by Hau (2006) in France and Lanne and Vesala (2010) in Germany, Japan and the USA. Further the deregulation of fixed commissions resulting in lower transaction costs caused a decrease of volatility in the USA (Jones \& Seguin, 1997). However, the opposite is exhibited by Liu and Zhu (2009), who found an increase of volatility by a commission deregulation.

Volume. Results of Pomeranets and Weaver (2012) indicates a rise (cut) in a STT resulting in a decline (increase) in trading volumes in the USA, therefore they conclude that the tax-rate negatively affects volumes. Baltagi et al. (2006) refined the question by quantifying the influence of the tax-rate on trading volume. They found that the elasticity of volume accounts to $100 \%$ of the tax rate, therefore doubling the tax rate halves the volume. A negative effect on volume is also observed by Umlauf (1993) in the Swedish STT scenario. Umlauf (1993) observed a decline in the Swedish market's volume together with a shift towards the UK markets. The reverse scenario, the cut of a transaction tax, was subject to Chou and Wang (2005). They find a significant increase in trading volumes after the rate cut, supporting the inverse relationship between tax rate and volume. Sinha and Mathur (2012) observe an inter-market shift from large to medium and small sized stocks after a STT. They conclude that investors might have changed their investment strategy. Contrary to these results $\mathrm{Hu}$ (1998) observed no significant change in the volume in four Asian markets.

Liquidity. Studies on the effects on liquidity in conjunction with a STT are scarce as of 2012. Pomeranets and Weaver (2012) apply the Amihud (2002) Amihud liquidity measure and find a direct relationship to the STT rate. To further validate their result they use the relative spread as suggested by Holden (2009). They discover that an increase (decrease) in the STT increases (decreases) market's relative spread levels. Together, as Amihud (2002) measure increases and spread widens, they conclude that liquidity after the introduction of a STT is worsened. A similar direct relationship between quoted spread and STT is discovered by Huang and Stoll (1997). In comparison to the study of Pomeranets and Weaver (2012) Chou and Wang (2005) studied the decrease of a transaction tax in the future markets of Taiwan.

We summarize the empirical literature as well as their findings in table 1 . To conclude, current research it can be stated that the effects accompanied by the introduction of a STT are not only diverse but also contrary. The results of the theoretical literature are most times subject to the assumptions made in the simulation or formal models. While these models are coherent and logically founded, empirical evidence can only be provided if these assumptions are met. As this is seldom possible, empirical literature follows well established and observable market quality parameters. While the effects on volatility in theoretical literature are inconsistent, empirical literature finds a tendency towards rising volatility caused by the introduction on a STT. Volumes were found to be declining at most times which might be an indicator of retreating market participants. Scarce research is available on the important matter of liquidity, which 
was found to be declining in two empirical articles. However, none of the studies provide evidence on the order book structure and which trader group did retreat. Further, to the best knowledge of authors, no attempt has been made to study the effects of a STT on inter-market price coordination. 
Table 1: Empirical Literature on the effects of a STT

\begin{tabular}{|c|c|c|c|c|c|c|c|}
\hline Study & Country & Type & Rate & Market & Volatility & Liquidity & Volume \\
\hline Baltagi et al. (2006) & China & STT & increase & Stock & increase* & - & decrease* \\
\hline Chou \& Wang (2005) & Taiwan & STT & decrease & Futures & no effect & increase* on cut & increase \\
\hline Green et al. (2000) & UK & TC & increase & Stock & $\begin{array}{l}\text { increase* (market vol.) } \\
\text { decrease* (fund. vol.) }\end{array}$ & - & - \\
\hline Hau (2006) & France & $\mathrm{TC}$ & increase & Stock & increase* & - & - \\
\hline $\mathrm{Hu}(1998)$ & $\begin{array}{l}\text { Hong Kong } \\
\text { Japan } \\
\text { Korea } \\
\text { Tawan }\end{array}$ & $\begin{array}{l}\text { STT } \\
\text { STT } \\
\text { STT } \\
\text { STT }\end{array}$ & $\begin{array}{l}\text { incr./decr. } \\
\text { incr./decr. } \\
\text { incr./decr. } \\
\text { incr./decr. }\end{array}$ & $\begin{array}{l}\text { Stock } \\
\text { Stock } \\
\text { Stock } \\
\text { Stock }\end{array}$ & $\begin{array}{l}\text { no effect } \\
\text { no effect } \\
\text { no effect } \\
\text { no effect }\end{array}$ & $\begin{array}{l}- \\
- \\
- \\
-\end{array}$ & $\begin{array}{l}\text { no effect } \\
\text { no effect } \\
\text { no effect } \\
\text { no effect }\end{array}$ \\
\hline Jarrell (1984) & USA & FCD & decrease & Stock & - & - & increase \\
\hline Jones \& Seguin (1997) & USA & FCD & decrease & Stock & decrease* & - & - \\
\hline Lanne \& Vesala (2010) & $\begin{array}{l}\text { Germany } \\
\text { Japan, USA }\end{array}$ & FCD & increase & FX & increase* & - & - \\
\hline Liu \& Zhu (2009) & Japan & FCD & decrease & Stock & increase* & - & - \\
\hline Liu (2007) & Japan & STT & decrease & Stock & - & - & \\
\hline Phylaktis \& Aristidou (2007) & Greece & STT & incr./decr. & Stock & $\begin{array}{l}\text { increase* on rise }^{*} \\
\text { (bull period) }\end{array}$ & - & no effect \\
\hline Pomeranets \& Weaver (2012) & USA & STT & incr./decr. & Stock & $\begin{array}{l}\text { increase* on rise }^{*} \\
\text { decrease* }^{*} \text { on rise }\end{array}$ & $\begin{array}{l}\text { increase* on cut } \\
\text { decrease* }^{*} \text { on rise }\end{array}$ & $\begin{array}{l}\text { increase* on cut } \\
\text { decrease* on rise }\end{array}$ \\
\hline Roll (1989) & 23 Countries & STT & incr./decr. & Stock & increase on rise & - & - \\
\hline Saporta \& Kan (1997) & UK & STT & incr./decr. & Stock & no changes & - & - \\
\hline Sinha \& Mathur (2012) & India & STT & increase & Stock & increase* & - & changes* \\
\hline Umlauf (1993) & Sweden & STT & increase & Stock & increase* & - & decrease* \\
\hline
\end{tabular}

Empirical results of a Securities Transaction Tax (STT), Transaction Costs (TC) and Fixed Commission Deregulation (FCD) on different parameters. Significant results are denoted by a star $\left({ }^{*}\right)$. 


\section{Anatomy of the French Transaction Tax}

In order to exhibit the analyzed regulatory event and to highlight its distinctions towards former STT implementations, this subsection will briefly recapitulate on the French STT concept. Following the British veto on the EU treaty changes of the Brussels summit in December 2012, the French government announced to regionally pioneer the EU-wide financial transaction tax. With the vote on the French First Amended Finance Bill on March $14^{\text {th }}, 2012$, the French parliament approved the taxation of financial transactions, which came into effect at August $1^{\text {st }}, 2012$ (Section XX: Taxe sur les transactions financiers - Article 235 ter ZD, French Government (2013)). The final guidelines have been released on August $2^{\text {nd }}, 2012$. The proposed STT is distributed into three separate taxation concepts, i.e. the taxation of the acquisition of equity securities, the taxation of HFT and the taxation of naked sovereign credit default swaps. While our assessment focuses on the effects on equity market transactions, foremost the first and second concept will be discussed. Additionally, within the French Second Amended Finance Bill European as well as American Depository Receipts will fall under the scope of the tax if traded after December $1^{\text {st }}, 2012$, which will not be discussed in this paper.

The first STT concept is applied only to the acquisition (one-sided) of securities that give, or may give, access to capital or voting rights in the issuing company. The condition for taxation is clarified under the definition of the "Eligible Instruments" as well as the "Eligible Markets" (PriceWaterhouseCoopers, 2012). The respective share has to be issued by a company with registered office in France and exhibit a market capitalization larger than $€ 1$ billion evaluated by January $1^{\text {st }}$ of the preceding year of taxation. In contrary to comparable taxes, the French STT is therefore limited to the most liquid French equity instruments. In addition, the security or instrument has to be admitted to trading on a French, European or foreign regulated market, within the meaning of Articles L. 421-4, L. 422-1 or L. 423-1 of the Monetary and Financial Code (French Government, 2013). If these criteria are met, the asset is considered eligible for taxation irrespective of where the transaction was negotiated or settled in order to avoid regulative arbitrage by migrating trading towards foreign exchanges.

In order to avoid cascading effects on market liquidity activities as well as public offerings, various exemptions from the STT are made to spare lit markets liquidity provision. The following list subsumes these exemptions clarifying the definition of "Eligible Instruments" and "Eligible Markets":

- Market making activities

- Transactions performed under liquidity agreements

- Exchangeable / Convertible Bonds

- Securities financing transactions

- Transaction performed by central securities depositories or clearinghouses

- Intra-Group, restructuring schemes and employee saving schemes

- Primary market acquisitions

These exemptions highlight the rigorous commitment to protect professional liquidity provision as market making as well as contractual liquidity provision is excluded from being taxed. In this light, it remains unclear how order book liquidity and decomposition may be affected due to the French STT and if professional liquidity provision could actually maintain market quality on their own.

Following the French Second Amended Finance Bill the tax rate has been doubled at a rate of $0.2 \%$ with a first deferred tax payment date at the end of November 2012 for all aggregated transaction executed within the previous months. The only taxable 
transaction will be the acquisition for consideration followed by the effectively transfer of the asset's ownership. The tax is based on the acquisition value (brokerage fees excluded) and is assessed on basis of the net buying position with regards to intra-day transactions (PriceWaterhouseCoopers, 2012). The assessment of the net buying position as well as the subsequent payment shall be done by the investment service provider (broker) or respective the securities account holder defined under L. 321-1 to L. 321-2 (French Government, 2013).

Considering the taxation concept to curb HFT activities as well as market disturbing activities, the French government clarified the application of the high frequency tax on August $6^{\text {th }}, 2012$. Therefore, HFT is subject to a $0.01 \%$ tax assessed on the number of securities on which orders have been cancelled or modified exceeding a fixed threshold multiplied by the average value of the security on one trading day (Article 235 ter ZD, French Government (2013)). This tax is applicable to HFT establishments located in France and only on equity securities of L. 212 (French Government, 2013) (again, market maker are exempted). HFT establishments are defined if the median latency between the sending and subsequent modification or cancellation of orders is less than 0.5 seconds, calculated over the month preceding the taxed transactions and if the rate of orders subsequently modified or cancelled in one day exceeds $80 \%$.

To subsume this taxation concept, it becomes evident that the French government finally took a very careful approach. In precluding any forms of professional liquidity provision from both concepts, the anxiety to significantly harm lit market liquidity provision becomes apparent. However, such a concept is not new. The taxes similarity to the UK foil becomes apparent with the similar scope of instruments as well as similar exceptions. However, in contrast to the territorial linkage of the Stamp Duty, the French STT addresses possible tax arbitrage with its extraterritorial scope. Additionally, by focusing on alternative STTs around the world (McCulloch \& Pacillo, 2011) a $0.2 \%$ tax could rather be considered low compared to similar implementations, e.g. the UK $(0.5 \%$ Stamp Duty) or Ireland (1.0\%), and likewise lower as proposed by academic studies, e.g. Pollin, Baker, and Schaberg (2003) with $0.5 \%$.

Regarding the tax to calm down speculative HFT strategies, this concept follows recent political (German High Frequency Trading Act, 2013) as well as academic (Government Office for Science - Foresight, 2012) proposals in concentrating on the rising divergence between individual trader's message creation and trade execution, also observed by various European exchanges. Therefore, the approach to tax HFT trading characteristics next to the basic transaction seems promising. However, likewise the currently discussed order-to-trade ratios, it remains unclear if the numerous criteria are strict enough to effectively restrain speculative HFTs and do not provide too many loopholes by the various classifications arising through the use of median values. Most important, as the tax is based on the net end-of-day buying position, such a foundation may significantly counteract HFT repression. As such concept particularly impedes sustainable long-term acquisitions while simultaneously inciting end-of-day inventory balancing, mostly done by HFTs (Gomber, Arndt, Lutat, \& Uhle, 2011), it remains doubtable if HFTs are actually affected.

\section{Research Design}

\section{Dataset 83 Sample Selection}

The French STT setup creates an unique opportunity to assess the effects on securities trading quality. Foremost the empirical lack of liquidity analysis as well as 
their contradicting results, together with the taxes liquidity exemption, yields a setup where market liquidity changes are not anticipated but a highly relevant topic. To give a holistic overview on the effect the STT regime induced on market quality, we rely on data retrieved from the Thomson Reuters Datascope Tick History. This data source covers times and sales tick by tick as well as order book tick data. According to the preceding section the STT is only applied to equities falling into the definition of "Eligible Instruments" traded on "Eligible Markets". Therefore the taxed assets have to share a location in France and exhibit a market capitalization in excess of $€ 1$ billion. In order to choose a heterogeneous and therefore representative sample, we rely on the constituents on the French blue chip index CAC 40. The CAC 40 represents the 40 most significant values among the highest industry-wide, capitalization-weighted enterprises of the NYSE Euronext Paris. Since four of these constituents do not fall into the scope of the STT due to their location outside France, these are excluded, leaving finally 36 constituents to the analysis. We collected market quality as well as order book indicators 10 days before and after the event day, i.e. $1^{\text {st }}$ of August, 2012, as well as 40 days before and after the event and aggregate them on a daily basis. Due to the two observation periods, we are able to distinguish between immediate and following effects as well as the effect's persistence.

Table 2: Thirds of the analyzed shares by market capitalization (in billion $€$ ) and price level (in €)

\begin{tabular}{|c|c|c|c|c|c|c|c|c|}
\hline & \multicolumn{4}{|c|}{ CAC 40} & \multicolumn{4}{|c|}{ DAX 30} \\
\hline & \multicolumn{2}{|c|}{ Market capitalization } & \multicolumn{2}{|c|}{ Price } & \multicolumn{2}{|c|}{ Market capitalization } & \multicolumn{2}{|l|}{ Price } \\
\hline \multirow{12}{*}{ Q1 } & SASY.PA & $€ 90.65$ & UNBP.PA & $€ 147.76$ & SAPG.DE & $€ 72.05$ & VOWG p.DE & $€ 135.41$ \\
\hline & TOTF.PA & $€ 90.43$ & LVMH.PA & $€ 124.08$ & VOWG_p.DE & $€ 70.99$ & LING.DE & $€ 124.34$ \\
\hline & LVMH SA & $€ 65.53$ & PRTP.PA & $€ 121.31$ & 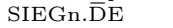 & $€ 68.08$ & MUVGn.DE & $€ 109.88$ \\
\hline & OREP.PA & $€ 62.30$ & AIRP.PA & $€ 94.97$ & BASFn.DE & $€ 60.01$ & ALVG.DE & $€ 83.79$ \\
\hline & BNPP.PA & $€ 51.51$ & OREP.PA & $€ 91.03$ & BAYGn.DE & $€ 55.42$ & MRCG.DE & $€ 81.69$ \\
\hline & GSZ.PA & $€ 40.06$ & TECF.PA & $€ 81.44$ & ALVG.DE & $€ 43.68$ & FREG.DE & $€ 80.09$ \\
\hline & DANO.PA & $€ 31.38$ & PERP.PA & $€ 80.50$ & BMWG.DE & $€ 42.14$ & SIEGn.DE & $€ 72.25$ \\
\hline & AIRP.PA & $€ 29.17$ & ESSI.PA & $€ 66.47$ & DAIGn.DE & $€ 39.02$ & CONG.DE & $€ 70.00$ \\
\hline & SCHN.PA & $€ 28.38$ & SASY.PA & $€ 59.41$ & DTEGn.DE & $€ 35.76$ & BMWG.DE & $€ 62.93$ \\
\hline & AXAF.PA & $€ 28.36$ & MICP.PA & $€ 53.54$ & DBKGn.DE & $€ 30.73$ & BASFn.DE & $€ 60.72$ \\
\hline & EDF.PA & $€ 26.00$ & DANO.PA & $€ 50.30$ & & & & \\
\hline & PERP.PA & $€ 22.55$ & SCHN.PA & $€ 46.88$ & & & & \\
\hline \multirow{12}{*}{ Q2 } & FTE.PA & $€ 21.46$ & VLLP.PA & $€ 41.44$ & EONGn.DE & $€ 28.13$ & ADSGn.DE & $€ 59.14$ \\
\hline & VIV.PA & $€ 21.28$ & PUBP.PA & $€ 39.65$ & HNKG_p.DE & $€ 23.68$ & BAYGn.DE & $€ 56.12$ \\
\hline & SOGN.PA & $€ 20.49$ & TOTF.PA & $€ 38.39$ & LING.DE & $€ 23.61$ & LXSG.DE & $€ 55.92$ \\
\hline & SGEF.PA & $€ 19.07$ & SGEF.PA & $€ 35.64$ & MUVGn.DE & $€ 23.02$ & FMEG.DE & $€ 54.59$ \\
\hline & PRTP.PA & $€ 17.37$ & RENA.PA & $€ 35.42$ & MRCG.DE & $€ 21.72$ & HNKG p.DE & $€ 53.81$ \\
\hline & UNBP.PA & $€ 15.57$ & LAFP.PA & $€ 33.86$ & RWEG.DE & $€ 19.35$ & BEIG.DE & $€ 51.18$ \\
\hline & ESSI.PA & $€ 15.42$ & BNPP.PA & $€ 32.63$ & DPWGn.DE & $€ 18.34$ & SAPG.DE & $€ 49.32$ \\
\hline & SGOB.PA & $€ 15.39$ & SGOB.PA & $€ 30.62$ & CONG.DE & $€ 15.87$ & DB1Gn.DE & $€ 44.17$ \\
\hline & CAGR.PA & $€ 14.43$ & CAPP.PA & $€ 29.58$ & FMEG.DE & $€ 15.76$ & DAIGn.DE & $€ 40.44$ \\
\hline & LAFP.PA & $€ 13.28$ & ALSO.PA & $€ 27.35$ & FREG.DE & $€ 15.05$ & HEIG.DE & $€ 39.17$ \\
\hline & CARR.PA & $€ 12.67$ & LEGD.PA & $€ 26.59$ & & & & \\
\hline & MICP.PA & $€ 12.37$ & ACCP.PA & $€ 25.13$ & & & & \\
\hline \multirow{12}{*}{ Q3 } & RENA.PA & $€ 10.62$ & BOUY.PA & $€ 21.81$ & BEIG.DE & $€ 14.93$ & SDFGn.DE & $€ 37.21$ \\
\hline & TECF.PA & $€ 9.64$ & SOGN.PA & $€ 19.89$ & ADSGn.DE & $€ 13.60$ & RWEG.DE & $€ 32.36$ \\
\hline & PUBP.PA & $€ 8.89$ & GSZ.PA & $€ 18.83$ & TKAG.DE & $€ 8.45$ & DBKGn.DE & $€ 30.74$ \\
\hline & ALSO.PA & $€ 8.20$ & EDF.PA & $€ 17.02$ & DB1Gn.DE & $€ 8.08$ & TKAG.DE & $€ 17.07$ \\
\hline & LEGD.PA & $€ 7.75$ & CARR.PA & $€ 16.08$ & CBKG.DE & $€ 7.43$ & EONGn.DE & $€ 16.99$ \\
\hline & ACCP.PA & $€ 5.62$ & VIV.PA & $€ 14.77$ & HEIG.DE & $€ 7.37$ & DPWGn.DE & $€ 13.98$ \\
\hline & BOUY.PA & $€ 5.58$ & AXAF.PA & $€ 11.05$ & SDFGn.DE & $€ 6.21$ & LHAG.DE & $€ 9.80$ \\
\hline & CAPP.PA & $€ 5.03$ & FTE.PA & $€ 10.81$ & IFXGn.DE & $€ 6.20$ & DTEGn.DE & $€ 8.89$ \\
\hline & VLLP.PA & $€ 4.35$ & SEVI.PA & $€ 9.66$ & LHAG.DE & $€ 5.51$ & IFXGn.DE & $€ 6.47$ \\
\hline & SEVI.PA & $€ 4.12$ & VIE.PA & $€ 9.63$ & LXSG.DE & $€ 5.33$ & CBKG.DE & $€ 1.54$ \\
\hline & VIE.PA & $€ 4.07$ & CAGR.PA & $€ 4.19$ & & & & \\
\hline & ALUA.PA & $€ 1.83$ & ALUA.PA & $€ 1.30$ & & & & \\
\hline
\end{tabular}

Overview of the sample selection. German and French equities are clustered by market capitalization and price levels to increase comparability among sub-samples 


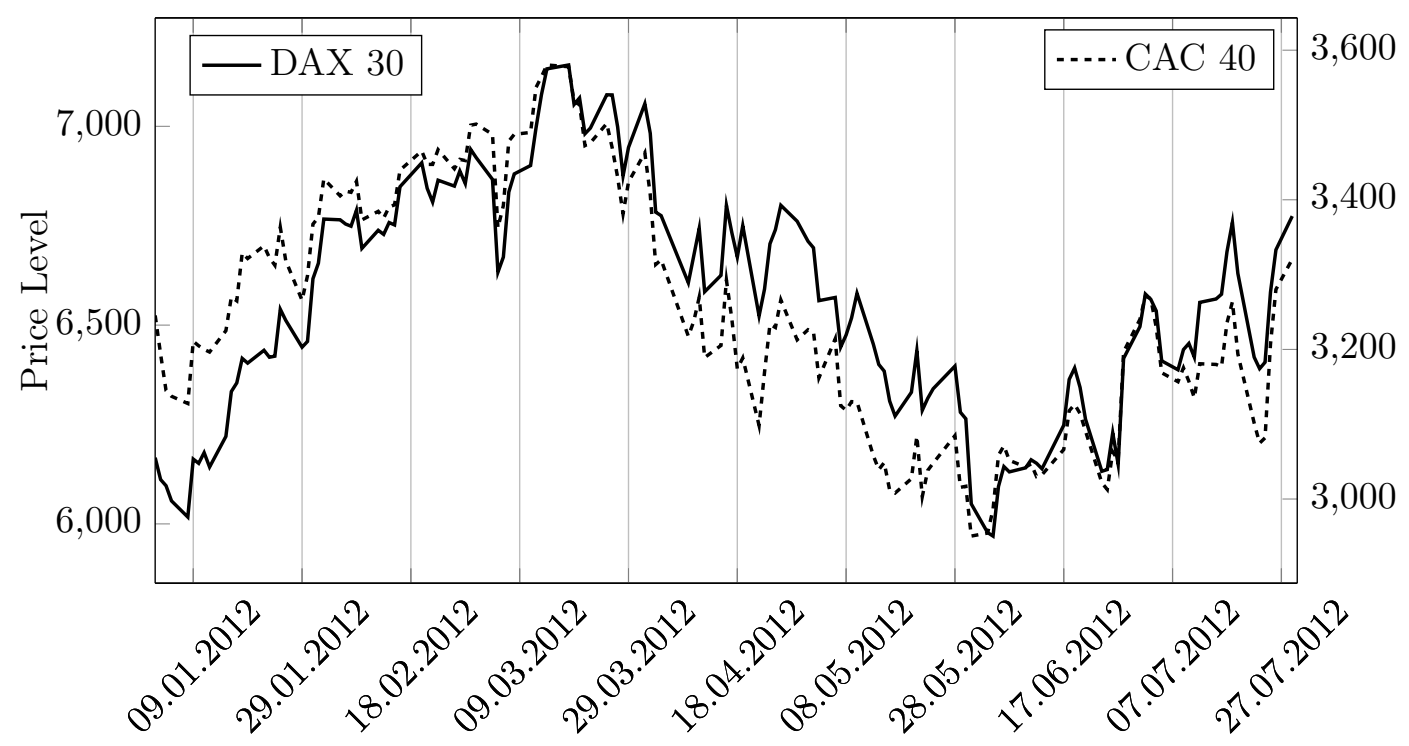

Figure 1. Price levels of DAX (left scale) and CAC 40 (right scale).

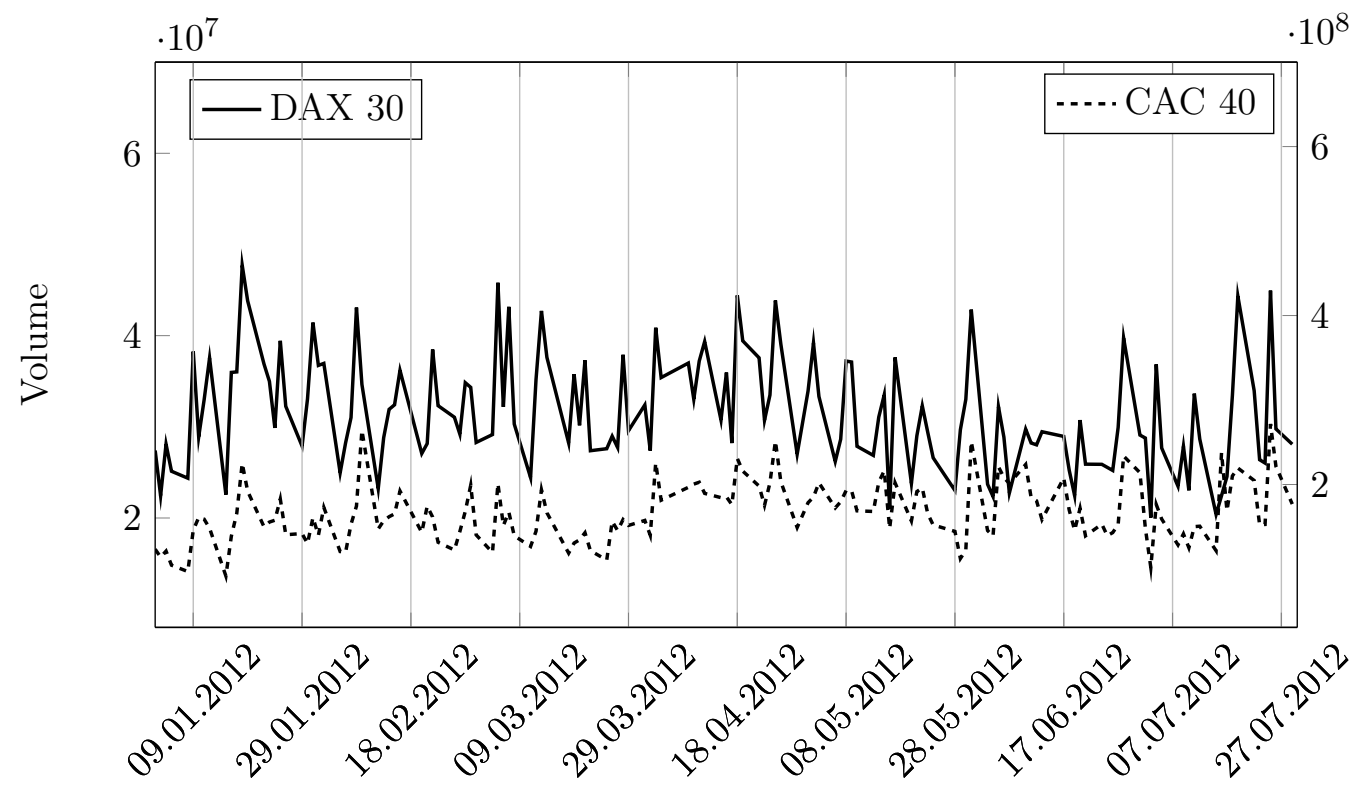

Figure 2. Volumes of the DAX (left scale) and the CAC 40 (right scale) constituents. 


\section{Methodology}

Regression Setup. The use of difference-in-differences (DiD) methods has become very widespread in empirical research determining the effects of political events or medical treatments (Snow, 1855). Imbens and Wooldridge (2007) outline the simplest setup as one where outcomes are observed for two groups and two time periods. One of the groups is exposed to a treatment in the second period but not in the first period. The second group is not exposed to the treatment in either periods. This removes biases between the treatment and control group within the second period that could be the result from permanent differences. Additionally, biases from comparisons over time in the treatment group that could be the result of trends are likewise removed (Imbens \& Wooldridge, 2007). This terminology is easily extended to a panel setup, where multiple treatment and control entities are observed over multiple pre- and post-event time series and thus allows for additional robustness within the time and entity dimension. Our methodology is guided by the following regression equation.

$$
y_{i t}=\alpha+x_{i t}+X_{i}+T_{t}+X_{i} * T_{t}+\epsilon_{i t}
$$

Where $X_{i}$ is a dummy variable taking the value 1 if the individual is in the treatment group and 0 if they are in the control group. Likewise $T_{t}$ is a dummy variable tracking the post- as well as pre-treatment period. We further include a full set of weekday effects alongside a trend control $\left(x_{i t}\right)$ and additionally control for changes in price levels, daily price movement as well as fluctuations within the traded volumes. Additionally, we account for the individual tick size and changes for each instrument. $\epsilon_{i t}$ equals the idiosyncratic, normal distributed error term. The quality of DiD is foremost determined by the quality of the control sample as the treatment effect is the calculated difference to the control sample (Imbens \& Wooldridge, 2007). Especially in securities trading there is no identical control reflecting every time-sensitive characteristic of an individual instrument. Different firm sizes, price levels, locations or macroeconomic events influence uniquely the asset's trading behavior and liquidity parameters making direct benchmarking non-trivial.

We utilize the most matchable index, the constituents of the German blue chip index DAX 30. DAX 30 and CAC 40 share strong similarities concerning market price levels (figure 1) and volume development (figure 2), industry coverage and most important, the European macroeconomic dependency due to the close geographic proximity. The index constituents share a similar distribution in price levels as well as enterprise values (calculated by market capitalization) as depicted in Table 2. Following various studies before (e.g. Lutat (2010)) and to further increase comparability between segments, we divide the sample into three equal sized sub-samples in order to compare similar priced and valued instruments with one another. This approach further allows for a distinct assignment of each individual effect to each price and liquidity segment. To further improve the robustness of our analysis we perform the DiD estimation within a symmetrical range of 40 days as well as a short ranged 10 days before and after the STT event. Being aware, that the control group could still bias our results, we additionally present the mere French pre- and post-event analysis. Regression results are estimated via ordinary least squares estimator using the fixed effects transformation to eliminate time-constant, unobserved effects as proposed by Wooldridge (2002) and clustered standard errors by instruments to account for instrument-wise autocorrelation as well as heteroscedasticity. 
Measuring Market Quality. We follow the guidance of the related literature and focus on changes in market quality parameters. Firstly, by analyzing the amount of executed trades on a daily basis we provide evidence on how trading activity is affected by the STT and therefore follow recent studies in this area (e.g. Sinha and Mathur (2012); Phylaktis and Aristidou (2007); Pomeranets and Weaver (2012)). Secondly, as proposed by the various studies before (e.g. Baltagi et al. (2006); Pomeranets and Weaver (2012); Umlauf (1993)) instrument volatility will be analyzed. Volatility is quantified in most studies by the standard deviation of the prices. We follow these common methodology to account for the prices' average fluctuation. Focusing on the prices maximum deviation, i.e. the amount of mispricing and overreaction, we also take into account use a daily high to low ratio calculated by dividing the highest against the lowest price (2).

$$
H L=\frac{\text { HighestPrice }}{\text { LowestPrice }}
$$

Thirdly, as most empirical studies concentrate only on volatility and price changes we shift our focus on order book liquidity characteristics. To prevent the influence of the price level to our measure we choose the relative spread. The relative spread represents the market's cost for immediacy, i.e. compensates professional market participants for continuously providing liquidity to the market. This measure is considered crucial within an assessment of a securities market's quality as the lower this compensation actually is, the cheaper trading is at this market becomes (L. Harris, 2003). The relative spread is calculated as follow:

$$
\text { RelativeSpread }=\frac{\text { BestAsk }- \text { BestBid }}{\frac{1}{2} *(\text { BestAsk }+ \text { BestBid })}
$$

To capture liquidity we also use the depth measure as proposed by Degryse, Jong, and Kervel (2011) - the Depth $(X)$. It quantifies the order volume around the midpoint measured in $€$. The calculation of $\operatorname{Depth}(X)$ is depicted at (4)where $X$ denotes the number of basis points around the midpoint $(M)$ and $j$ the price level in the order book. The Depth measure indicates the market's ability to overcome even large executions without leading to subsequent order imbalances and subsequent price variability. A market with a high depth level will prove to be more resilient and dampen executionbased market price impact more effectively than a market with only low depth level.

$$
\begin{aligned}
\operatorname{DepthAsk}(X) & =\sum_{j=1}^{j} * \operatorname{Price}_{j}^{A s k} * \text { Quantity }_{j}^{A s k} \mid\left(\text { Price }_{j}^{A s k}<M *(1+X)\right), \\
\operatorname{DepthBid}(X) & =\sum_{j=1}^{j} * \operatorname{Price}_{j}^{\text {Bid }} * \text { Quantity }_{j}^{\text {Bid }} \mid\left(\text { Price }_{j}^{\text {Bid }}<M *(1+X)\right), \\
\operatorname{Depth}(X) & =\operatorname{DepthAsk}(X)+\operatorname{DepthBid}(X)
\end{aligned}
$$

Following this path, we provide the respective results within separate regressions for each focus. Additionally, taking into account the fragmentation process of the European market landscape, we analyze inter-market information transmission after the STT introduction.

\section{Results}

\section{The Effect on Market Quality}

Impact on Trading Activity. The French STT has increased the cost of trading and therefore might reduce incentives to trade or even to quote. Especially traders relying 
on high execution rates and small profit margins, e.g. HFTs and arbitrageurs, will find trade or quote opportunities to be unfavorable if the transaction tax consumes the profit and therefore makes their business model obsolete. Similarly, as argued by Culp (2010), a STT that raises the cost of trading in country A relative to country B will likely induce a shift of trading volume from A towards B. Although the French legislative body eliminated such regulatory arbitrage, it is likely that international portfolios will substitute French shares due to the additional transaction costs. Therefore, we aim at first at changes within average market activity initiated by the introduction of the French STT. We apply the proposed regression analysis on the dependent variables executed trades as well as traded volumes. As the only taxable transaction will be the acquisition, a decline in the observed number of trades seems reasonable. However, if traded volumes are affected remains questionable. The analysis accounts for a shortand long-term observation period with and without the German benchmark. Tables 3 and 4 exhibit the results for all sub-samples as well as the relative changes.

Table 3: Trading Activity - Fixed Effects Regression (20 days)

\begin{tabular}{|c|c|c|c|c|c|c|c|c|c|}
\hline & \multicolumn{5}{|c|}{ Executed Trades } & \multicolumn{4}{|c|}{ Traded Volume } \\
\hline & \multicolumn{3}{|c|}{ no_contr } & \multicolumn{2}{|l|}{ contr } & \multicolumn{2}{|l|}{ no_contr } & \multicolumn{2}{|l|}{ contr } \\
\hline \multicolumn{10}{|c|}{ Market Capitalization Cluster } \\
\hline \multirow[b]{2}{*}{ Change Q1 } & abs. & -357 & & $-2,039$ & $* * *$ & 338,183 & & $-426,985$ & \\
\hline & rel. & $-3 \%$ & & $-16 \%$ & & $7 \%$ & & $-9 \%$ & \\
\hline \multirow{2}{*}{ Change Q2 } & abs. & -659 & & $-1,876$ & $* * *$ & 147,568 & & $-1,924,79$ & \\
\hline & rel. & $-8 \%$ & & $-22 \%$ & & $4 \%$ & & $-5 \%$ & \\
\hline \multirow{2}{*}{ Change Q3 } & abs. & -166 & & $-1,899$ & $* * *$ & $-9,631$ & & $-1,760,578$ & \\
\hline & rel. & $-2 \%$ & & $-28 \%$ & & $0 \%$ & & $-33 \%$ & \\
\hline \multicolumn{10}{|c|}{ Price Cluster } \\
\hline \multirow{2}{*}{ Change Q1 } & abs. & $-2,297$ & $* * *$ & $-2,534$ & $* * *$ & $-418,532$ & $* *$ & $-306,073$ & $* *$ \\
\hline & rel. & $-27 \%$ & & $-30 \%$ & & $-34 \%$ & & $-25 \%$ & \\
\hline \multirow{2}{*}{ Change Q2 } & abs. & $-1,084$ & & $-2,195$ & $* * *$ & $-232,365$ & & $-377,653$ & \\
\hline & rel. & $-10 \%$ & & $-21 \%$ & & $-8 \%$ & & $-14 \%$ & \\
\hline \multirow{2}{*}{ Change Q3 } & abs. & 1,788 & & -914 & & $1,743,602$ & & $-1,703,698$ & \\
\hline & rel. & $19 \%$ & & $-28 \%$ & & $17 \%$ & & $-17 \%$ & \\
\hline
\end{tabular}

Aggregated FE regression results for the coefficient on the STT indicator and relative changes on the dependent variable executed trades and traded volume grouped by market capitalization as well as price thirds 10 trading days before and after August $1^{\mathrm{st}}$, 2012. Regressions are performed on the French subsample (no_contr) and together with the German subsample (contr). ***,** and * denote significance at the 1,5 and 10 percent levels, respectively.

Since the results reveal different effects we focus at first only on the French situation without the German benchmark. Most notable, within 10 days after the introduction the highest priced instruments show a significant drop in executed trades which decline by $27 \%$ on average. Although the other liquidity and price classes show negative developments within this period, these changes are not significant different from zero. Within 40 days after the event the effects on executed trades become uniformly significant. We observe a homogeneous decrease in executed trades throughout all liquidity and price clusters on average by $26 \%$ after 40 days. Most notably, the highest priced and likewise the lowest liquid instruments seem to be affected the most. By including the German 
Table 4: Trading Activity - Fixed Effects Regression (80 days)

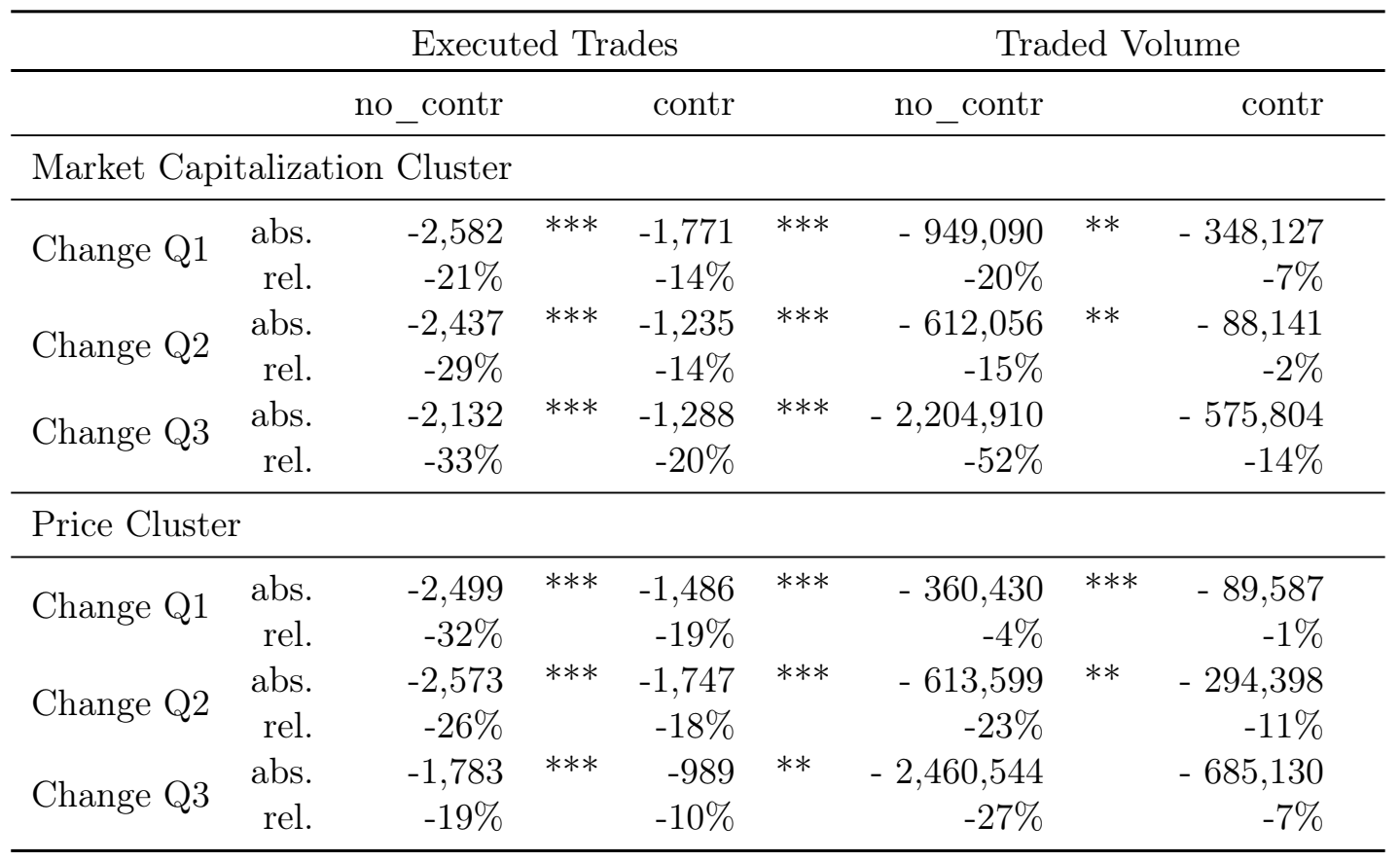

Aggregated FE regression results for the coefficient on the STT indicator and relative changes on the dependent variable executed trades and traded volume grouped by market capitalization as well as price thirds 40 trading days before and after August $1^{\text {st }}$, 2012. Regressions are performed on the French subsample (no contr) and together with the German subsample (contr). ***, ** and * denote significance at the 1, 5 and 10 percent levels, respectively.

benchmark into this consideration, we are able to observe additional effects. As French values did not share the German developement, the STT effects becomes significant within all sub-classes even within the short-term period (average 21\%) 3. Within 40 days after the introduction the coefficients at the STT indicator remain significant negative although relative decreases are reduced (average 16\%). Figure 3 depicts the time series developement of the number of trades for the respective time period averaging over both indices. The figure supports our results as the STT effects peaks distinctivly in August, while September shows reversion towards pre-STT dendencies which is coherent with the decrease in relative values of our benchmark results.

Similar effects account for traded volumes as again the highest priced instrument saw a significant drop within the short-run but more persistently in the long-run if only French instruments are analyzed. When evaluating trading activity relative to the development of the German benchmark, the deterioration in executed shares within all price and liquidity classes looses significance as German stocks did experience a similar development. However, the coefficients are negative within all subclasses in the long-run period. Mainly due to the high variability in executed shares per day, significance of the results vanishes in the benchmark analysis. Figure 4 again depicts traded volumes for the respective time period. Contrary to number of trades the STT's effect on executed volumes seem to be mostly pronounced in late September where August shows little deviation to the pre-STT level, which is in line with our short- and long-term results.

Summarizing these results, we find that trading activity is immediately reacting to the STT as number of trades are dropping drastically within 10 days after the introduction of the STT. Concerning traded volumes, results remain more opaque as deviations 


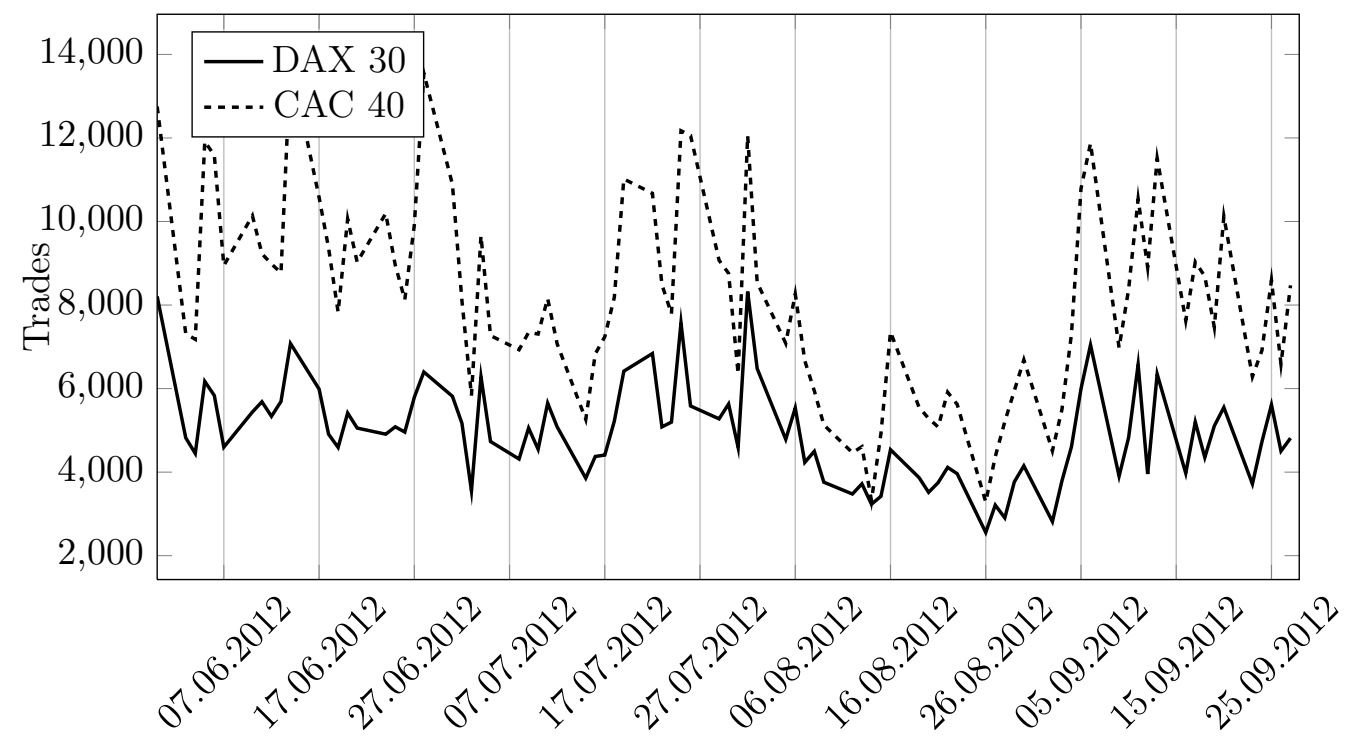

Figure 3. Amount of Trades per Day of the DAX and CAC 40.

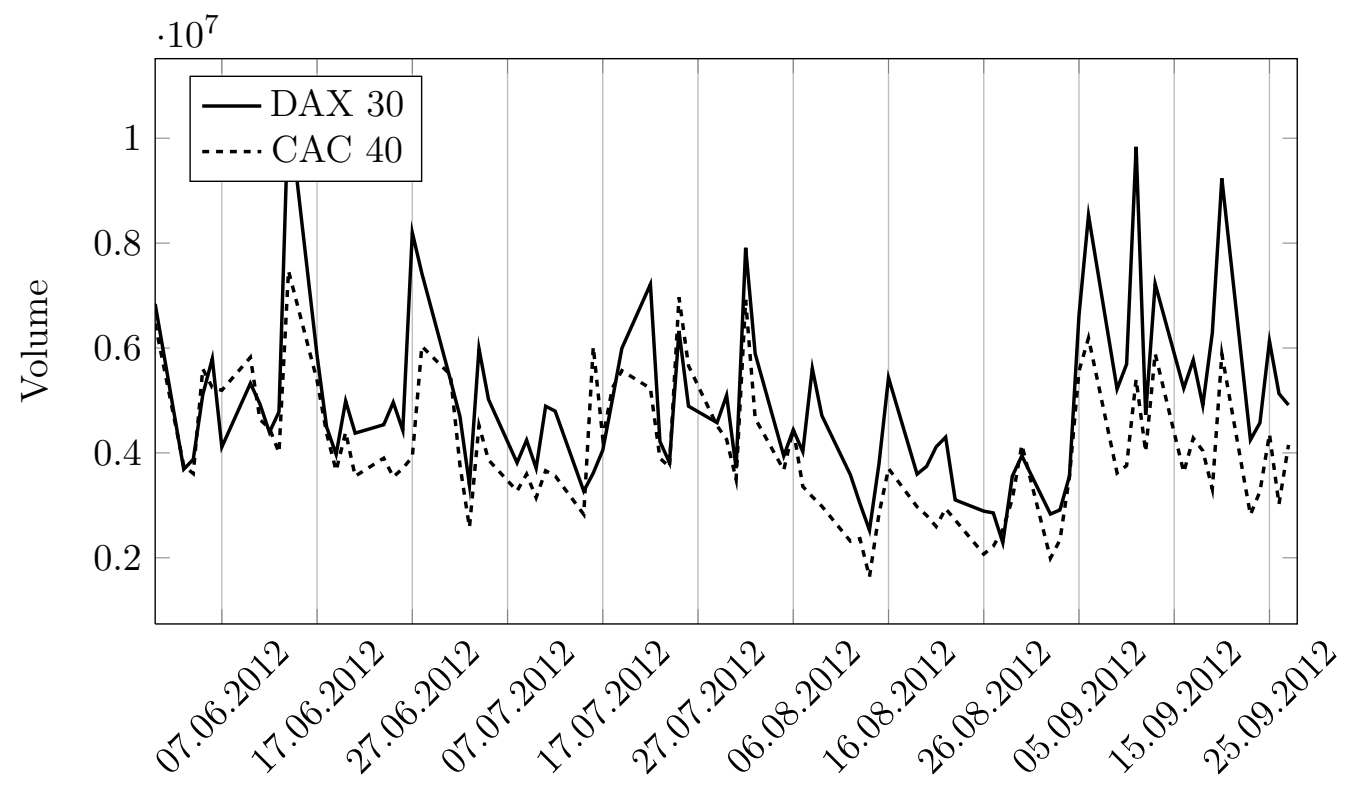

Figure 4. Volume of the DAX and CAC 40 constituents. 
from the benchmark only become apparent in the late of September. As the decline in trades is consistent with the general academic assumption and other empirical findings provided by earlier studies (Umlauf, 1993; Baltagi et al., 2006; Pomeranets \& Weaver, 2012) these results do not seem to be surprising. However, based on these findings, trade sizes must have increased shortly after the introduction of the STT. 
Impact on Trading Volatility. Following the research stream of the related literature, price volatility is found to be highly affected by STTs due to the changes in transaction costs. Increased variability of the asset prices indicate that the level of uncertainty about the true value of the respective asset has changed. The high volatility would therefore bias an investor's evaluation and potentially result in incorrect investment decisions (L. Harris, 2003). The differences between our two measures (standard deviation and high to low ratio) become apparent as the high to low ratio is only affected by the daily maximum and minimum values, whereas these values are under-weighted within the standard deviation. We again apply the DiD methodology, clustered by market capitalization and prices within 10 days and 40 days before and after the event.

Table 5: Market Volatiltiy Levels - Fixed Effects Regression (20 days)

\begin{tabular}{|c|c|c|c|c|c|c|c|c|}
\hline & & \multicolumn{3}{|c|}{ Standard Deviation } & \multicolumn{4}{|c|}{ High to Low Ratio } \\
\hline & & no_contr & & contr & no_contr & & contr & \\
\hline \multicolumn{9}{|c|}{ Volume Cluster } \\
\hline \multirow{2}{*}{ Change Q1 } & abs. & 0.0204 & & 0.0426 & 0.0083 & $*$ & 0.0011 & \\
\hline & rel. & $7 \%$ & & $14 \%$ & $1 \%$ & & $0 \%$ & \\
\hline \multirow{2}{*}{ Change Q2 } & abs. & -0.0050 & & -0.0012 & 0.0019 & & -0.0020 & \\
\hline & rel. & $-1 \%$ & & $0 \%$ & $0 \%$ & & $0 \%$ & \\
\hline \multirow{2}{*}{ Change Q3 } & abs. & -0.0366 & & -0.0260 & -0.0014 & & -0.0054 & $* *$ \\
\hline & rel. & $-17 \%$ & & $-12 \%$ & $0 \%$ & & $-1 \%$ & \\
\hline \multicolumn{9}{|c|}{ Price Cluster } \\
\hline \multirow{2}{*}{ Change Q1 } & abs. & -0.0547 & & 0.0115 & -0.0010 & & -0.0009 & \\
\hline & rel. & $-11 \%$ & & $2 \%$ & $0 \%$ & & $0 \%$ & \\
\hline \multirow{2}{*}{ Change Q2 } & abs. & -0.0409 & & -0.0027 & -0.0019 & & -0.0034 & \\
\hline & rel. & $-16 \%$ & & $-1 \%$ & $0 \%$ & & $0 \%$ & \\
\hline \multirow{2}{*}{ Change Q3 } & abs. & 0.0296 & $* *$ & 0.0047 & 0.0111 & $* *$ & -0.0014 & \\
\hline & rel. & $27 \%$ & & $4 \%$ & $1 \%$ & & $0 \%$ & \\
\hline
\end{tabular}

Aggregated FE regression results for the coefficient on the STT indicator and relative changes on the dependent variable standard deviation of trade prices and high to low ratio grouped by market capitalization as well as price thirds 10 trading days before and after August $1^{\mathrm{st}}$, 2012. Regressions are performed on as well as price thirds 10 trading days before and after August $1^{\text {st }}$, 2012. Regressions are performed on
the French subsample (no contr) and together with the German subsample (contr). ***, ** and * denote significance at the 1,5 and 10 percent levels, respectively.

As shown in Tables 5 and 6 changes in volatility remain more opaque compared to changes in trading activity. Within the short-range period, no distinct effects could be attributed to the introduction of the STT. French development alone, likewise in comparison to the German benchmark shows no evidence of a significant changes. Within the long range observation period only the lowest priced as well as the instruments with lowest liquidity show a significant improvement in both volatility parameters if the focus remains on the French values alone. Though, as the German instruments experienced a similar improvement in standard deviation and high to low ratio, this effect does not remain a pure French incident. These results are in line with the time series development shown in Figures 5 and 6 . However, in the light of these results, the conclusion that the French STT has an increasing effect volatility can not be drawn. Further, these results give no indication if the lost order volume and trading activity was of distinct or 
Table 6: Market Volatiltiy Levels - Fixed Effects Regression (80 days)

\begin{tabular}{|c|c|c|c|c|c|c|c|c|}
\hline & & \multicolumn{4}{|c|}{ Standard Deviation } & \multicolumn{3}{|c|}{ High to Low Ratio } \\
\hline & & no_contr & & contr & & no_contr & & contr \\
\hline \multicolumn{9}{|c|}{ Market Capitalization Cluster } \\
\hline \multirow{2}{*}{ Change Q1 } & abs. & -0.0017 & & 0.0329 & $* *$ & -0.0006 & & 0.0012 \\
\hline & rel. & $-1 \%$ & & $13 \%$ & & $0 \%$ & & $0 \%$ \\
\hline \multirow{2}{*}{ Change Q2 } & abs. & -0.0265 & & 0.0149 & & -0.0025 & $* *$ & 0.0008 \\
\hline & rel. & $-10 \%$ & & $5 \%$ & & $0 \%$ & & $0 \%$ \\
\hline \multirow{2}{*}{ Change Q3 } & abs. & -0.0367 & $* * *$ & -0.0129 & & -0.0060 & $* * *$ & -0.0012 \\
\hline & rel. & $-20 \%$ & & $-7 \%$ & & $-1 \%$ & & $0 \%$ \\
\hline \multicolumn{9}{|c|}{ Price Cluster } \\
\hline \multirow{2}{*}{ Change Q1 } & abs. & -0.0128 & & 0.0228 & & -0.0006 & & 0.0014 \\
\hline & rel. & $-3 \%$ & & $6 \%$ & & $0 \%$ & & $0 \%$ \\
\hline \multirow{2}{*}{ Change Q2 } & abs. & -0.0525 & $* * *$ & 0.0161 & & -0.0046 & $* * *$ & -0.0005 \\
\hline & rel. & $-24 \%$ & & $7 \%$ & & $0 \%$ & & $0 \%$ \\
\hline \multirow{2}{*}{ Change Q3 } & abs. & -0.0105 & $* *$ & 0.0021 & & -0.0038 & $*$ & -0.0009 \\
\hline & rel. & $-11 \%$ & & $2 \%$ & & $0 \%$ & & $0 \%$ \\
\hline
\end{tabular}

\footnotetext{
Aggregated FE regression results for the coefficient on the STT indicator and relative changes on the dependent variable variable standard deviation of trade prices and high to low ratio grouped by market capitalization as well as price thirds 40 trading days before and after August $1^{\text {st }}$, 2012. Regressions are performed on the French subsample (no contr) and together with the German subsample (contr). ***, ** and * denote significance at the 1,5 and $1 \overline{0}$ percent levels, respectively.
}

disorienting nature, as argued by Summers and Summers (1989) and Stiglitz (1989). 


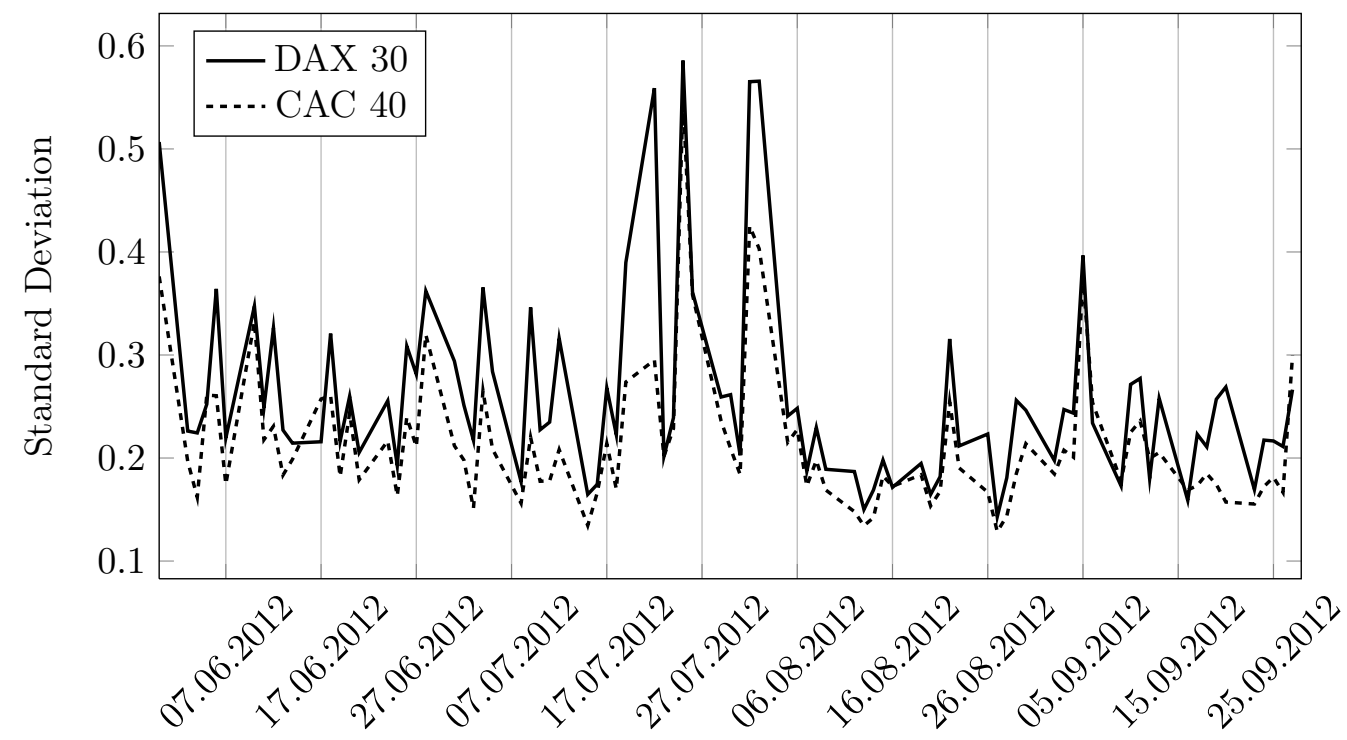

Figure 5. Standard Deviation of the DAX and CAC 40 constituents. 


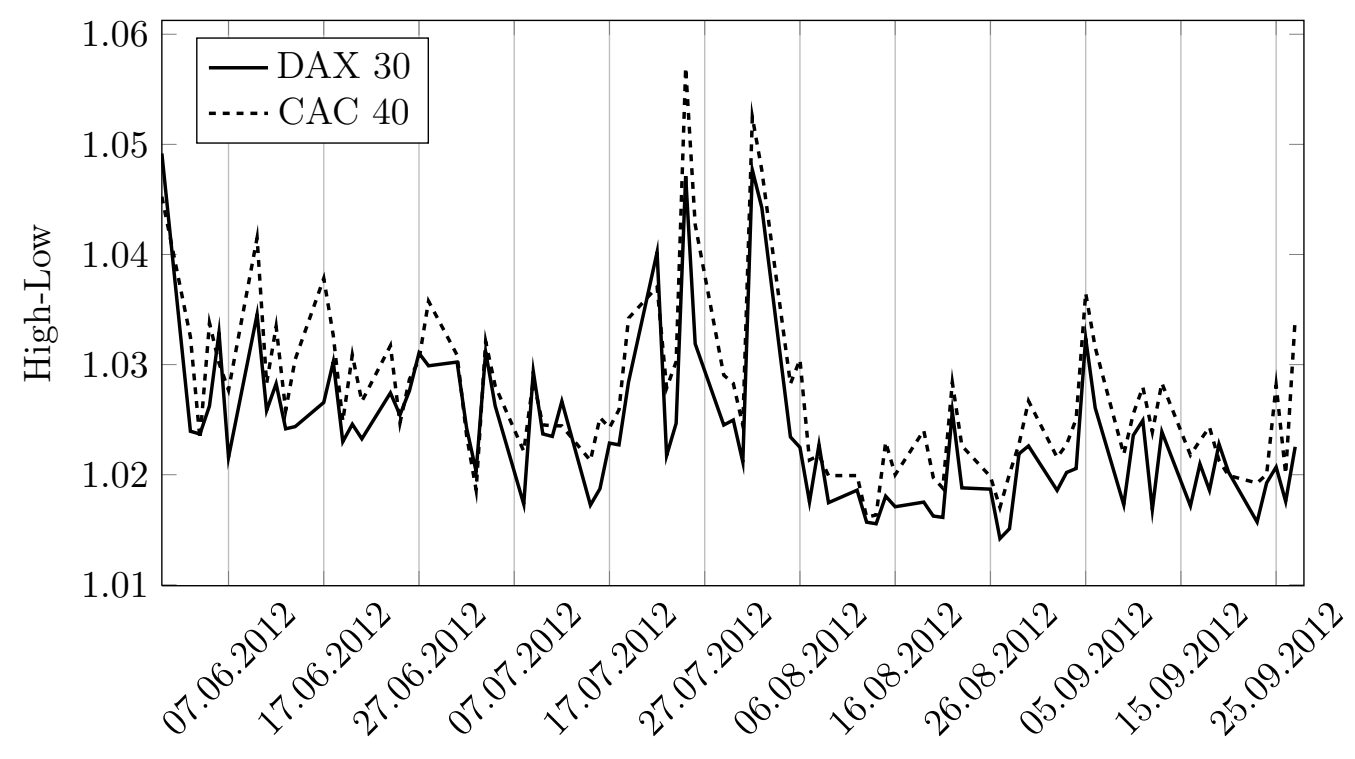

Figure 6. High-Low of the DAX and CAC 40 constituents.

Impact on Liquidity. Academic studies empirically analyzing the effects of STTs mostly focus on changes in trading activity as well as price volatility effects, especially as trade executions seem to be the most relevant activity influenced by the STT. However, an increase in transaction costs may additionally affect a trader's willingness to quote and therefore directly influence order book liquidity supply. The theoretical debate does not provide consistent conclusion so far and empirical studies analyzing liquidity impacts are scarce as of 2012. Most notably, as the French STT considers manifold exemptions in the case trading activity is related to professional liquidity provision, the results may indicate if such articles are reasonable in order to spare market quality. We therefore raise the question, if the decline in execution activity is also accompanied by a deterioration of the market's liquidity supply. We measure liquidity by relative spread and depth. Additionally, by focusing on the order book decomposition, we will give indication about the quality of the lost liquidity supply. Since any change in the relative spread level will additionally affect the Depth, we additionally control for changes within the relative spread in this regression. Tables 7 and 8 aggregate our results for relative spread and $\operatorname{Depth}(10)$, again for the short- and long term period as well as with and without the German benchmark.

Again, we start by analyzing the effects without the German benchmark. Within the short-run (10 days), no distinct effect on the relative spread becomes apparent. Only in the long-run an increase of the French instrument's relative spread becomes significant spanning all price and liquidity classes. Focusing on order book depth, we observe a critical thinning among the instruments immediately after the adaption of the STT that becomes more distinct within the following days. In comparison to the development of the German DAX instruments, differences become more persistent and apparent even within the short-run period. By comparing with the German benchmark instruments, which had a more positive development in the relative spread and depth levels, the STT's effect on relative spread becomes also apparent in the short-run. It is obvious that the real STT effect on market liquidity lies in between those two approaches. 
Table 7: Market Liquidity Levels - Fixed Effects Regression (20 days)

\begin{tabular}{lrrrrrrrr}
\hline & \multicolumn{3}{c}{ Relative Spread } & \multicolumn{3}{c}{ Depth(10) } \\
\hline & \multicolumn{3}{c}{ no_contr } & contr & no_contr & contr & \\
\hline \multicolumn{2}{l}{ Market Capitalization Cluster } & & & & & & \\
\hline \multirow{2}{*}{ Change Q1 } & abs. & -0.0002 & 0.0001 & $* *$ & $-120,948$ & $* * *$ & $-151,643$ & $* * *$ \\
& rel. & $-25 \%$ & $15 \%$ & $-16 \%$ & & $-20 \%$ & \\
Change Q2 & abs. & -0.0001 & 0.0000 & $-71,656$ & $* *$ & $-64,320$ & \\
& rel. & $-17 \%$ & $3 \%$ & $-16 \%$ & & $-14 \%$ & \\
Change Q3 & abs. & 0.0000 & 0.0001 & $* * *$ & $-31,189$ & $* *$ & $-43,412$ & $* *$ \\
& rel. & $2 \%$ & $15 \%$ & & $-13 \%$ & & $-18 \%$ & \\
\hline \multirow{2}{*}{ Price Cluster } & & & & & & & & \\
\hline \multirow{2}{*}{ Change Q1 } & abs. & -0.0001 & 0.0001 & $* *$ & $-151,532$ & $* * *$ & $-137,773$ & $* * *$ \\
& rel. & $-19 \%$ & $7 \%$ & & $-22 \%$ & & $-20 \%$ & \\
Change Q2 & abs. & 0.0000 & 0.0001 & $* *$ & $-50,556$ & $* * *$ & $-88,629$ & $* * *$ \\
& rel. & $-1 \%$ & $11 \%$ & & $-12 \%$ & & $-20 \%$ & \\
Change Q3 & abs. & -0.0002 & 0.0001 & $* *$ & $-48,355$ & $* *$ & $-51,500$ & $* *$ \\
& rel. & $-17 \%$ & $12 \%$ & & $-16 \%$ & & $-17 \%$ & \\
\hline
\end{tabular}

Aggregated FE regression results for the coefficient on the STT indicator and relative changes on the dependent variable Relative Spread and Depth(10) grouped by market capitalization as well as price thirds 10 trading days before and after August $1^{\text {st }}$, 2012. Regressions are performed on the French subsample (no contr) and together with the German subsample (contr). ***, ** and * denote significance at the 1, 5 and 10 percent levels, respectively.

Table 8: Market Liquidity Levels - Fixed Effects Regression (80 days)

\begin{tabular}{lcrrrrrrrr}
\hline & \multicolumn{3}{c}{ Relative Spread } & \multicolumn{5}{c}{ Depth(10) } \\
\hline & \multicolumn{3}{c}{ no_contr } & & contr & no_contr & & contr & \\
\hline \multicolumn{2}{l}{ Market Capitalization Cluster } & & & & & & & \\
\hline \multirow{2}{*}{ Change Q1 } & abs. & 0.0001 & $* * *$ & 0.0001 & $* * *$ & $-149,399$ & $* * *$ & $-170,867$ & $* * *$ \\
& rel. & $13 \%$ & & $11 \%$ & & $-19 \%$ & & $-22 \%$ & \\
Change Q2 & abs. & 0.0001 & $* *$ & 0.0001 & $*$ & $-98,522$ & $* *$ & $-127,968$ & $* *$ \\
& rel. & $14 \%$ & & $7 \%$ & & $-23 \%$ & & $-29 \%$ & \\
Change Q3 & abs. & 0.0002 & $*$ & 0.0002 & $* * *$ & $-24,657$ & $*$ & $-94,194$ & $* * *$ \\
& rel. & $18 \%$ & & $16 \%$ & & $-10 \%$ & & $-40 \%$ & \\
\hline \multirow{2}{*}{ Price Cluster } & & & & & & & & & \\
\hline \multirow{2}{*}{ Change Q1 } & abs. & 0.0001 & $* *$ & 0.0001 & $* *$ & $-187,683$ & $* * *$ & $-129,146$ & $* * *$ \\
& rel. & $18 \%$ & & $9 \%$ & & $-28 \%$ & & $-20 \%$ & \\
\multirow{2}{*}{ Change Q2 } & abs. & 0.0001 & $* * *$ & 0.0001 & $* * *$ & $-94,008$ & $* *$ & $-131,405$ & $* * *$ \\
& rel. & $15 \%$ & & $15 \%$ & & $-20 \%$ & & $-28 \%$ & \\
Change Q3 & abs. & 0.0001 & $* *$ & 0.0001 & $*$ & $-41,258$ & $* * *$ & $-103,512$ & $* * *$ \\
& rel. & $15 \%$ & & $15 \%$ & & $-13 \%$ & & $-32 \%$ & \\
\hline
\end{tabular}

Aggregated FE regression results for the coefficient on the STT indicator and relative changes on the dependent variable Relative Spread and Depth(10) grouped by market capitalization as well as price thirds 40 trading days before and after August $1^{\text {st }}$, 2012. Regressions are performed on the French subsample (no_contr) and together with the German subsample (contr). ***, ** and * denote significance at the 1,5 and 10 perceñt levels, respectively. 
Spread levels increase up to $18 \%$ within the lowest liquidity and highest price classes in the long-run, compared to the German benchmark average relative spreads are widened by $10 \%$. Likewise the developements in trade execution, Figure 7 gives indication that the effect's peak was located within the first two weeks of August, followed by a slide reversion. Order book liquidity within a range of 10 basis points arount the midpoint decreases by an average $18 \%$ to $28 \%$. This time, analizing time series developement depicted in Figure8 as well as the similar relative deterioration within 40 days, the decrease in order book depth is constantly persistent throughout the entire observation period. These results testify the self-enforcing effects on overall transaction cost due to the introduction of a STT (Matheson, 2011; Habermeier \& Kirilenko, 2001). However, the analysis so far does not provide sufficient detail on possible order book composition changes, which is why we extent our analysis. 


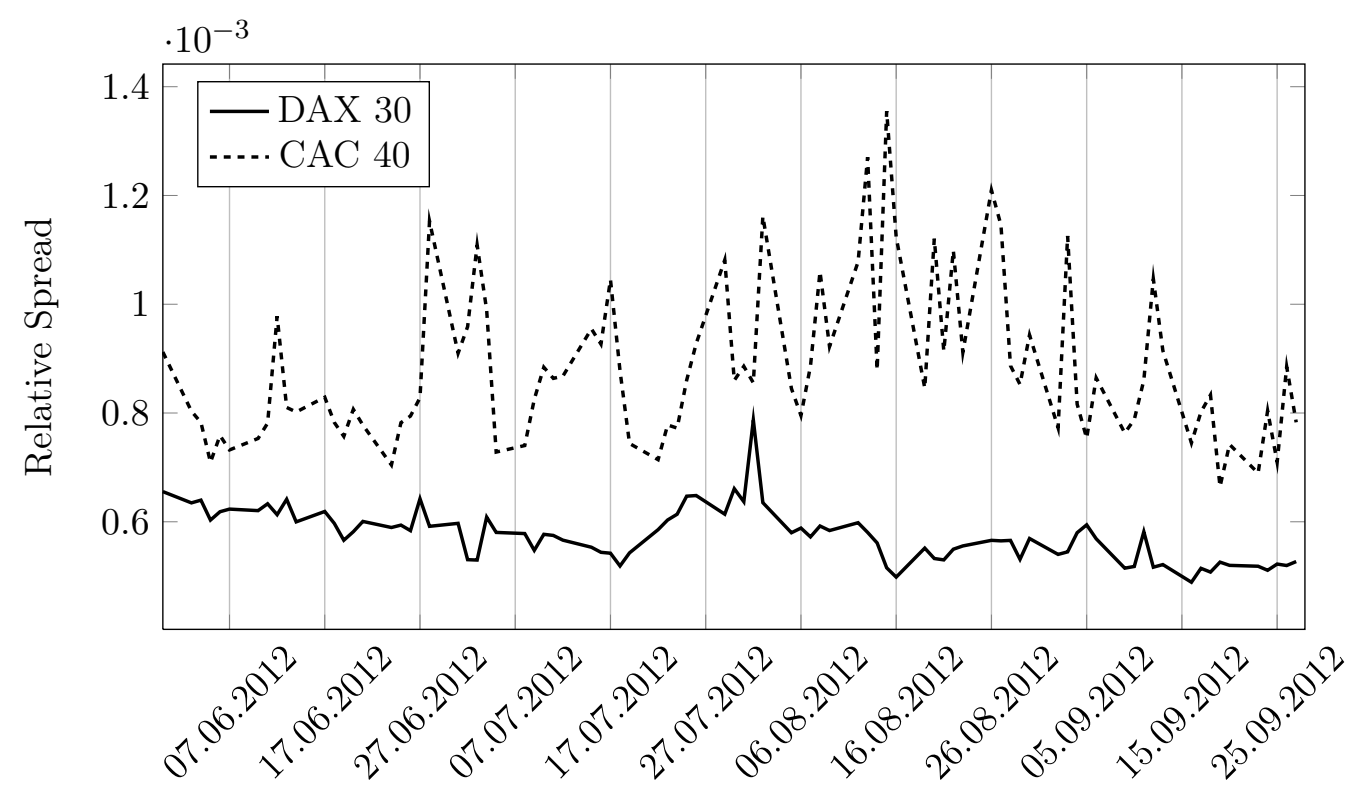

Figure \%. Relative Spread of the DAX and CAC 40 constituents.

We will decompose the Depth(10) measure into two sub-classes, i.e. Depth(5) and Depth(5-10), respectively 5 and 5 to 10 basis points from the order books midpoint. This way we are able to shed more light onto the order book's volume development due to the French STT. Again, we will control for changes in the relative spread to distinguish between mere spread and depth changes. Tables 9 and 10 highlight the proposed approach on the order book's volume composition.

Most interesting within this decomposition, the decline in order book depth, even within 10 days, is observable within the upper and lower order book liquidity level almost symmetrically. Focusing only on relative values indicates an equal decline in the upper and lower order book sections. This means, although designed to spare liquidity provision and therefore sustain market quality levels, the decline in order book volume hit the open order book equally intensive at the top and bottom levels. Likewise, observable within 10 days before and after, results get more decisive within the long event window. Again, we visualize the time series developments in Figures reffig:depth15 and reffig:depth510.

Our results indicate that the mere taxation of transactions does not only affect average trading demand but rather massively deteriorate order book liquidity levels as liquidity supply is massively retreating. Although some of the effects, like spread increase and trade decline, seem to peak especially shortly after the STT introduction, depth levels and volumes decline show persistent duration. However, our approach so far only focused on the liquidity of a single market. As the fragmented European market system is heavily based on the connectivity of the manifold liquidity sources, effects on intermarket information coordination is highly desirable. We will focus on the information transmission between fragmented markets in the next subsection. 


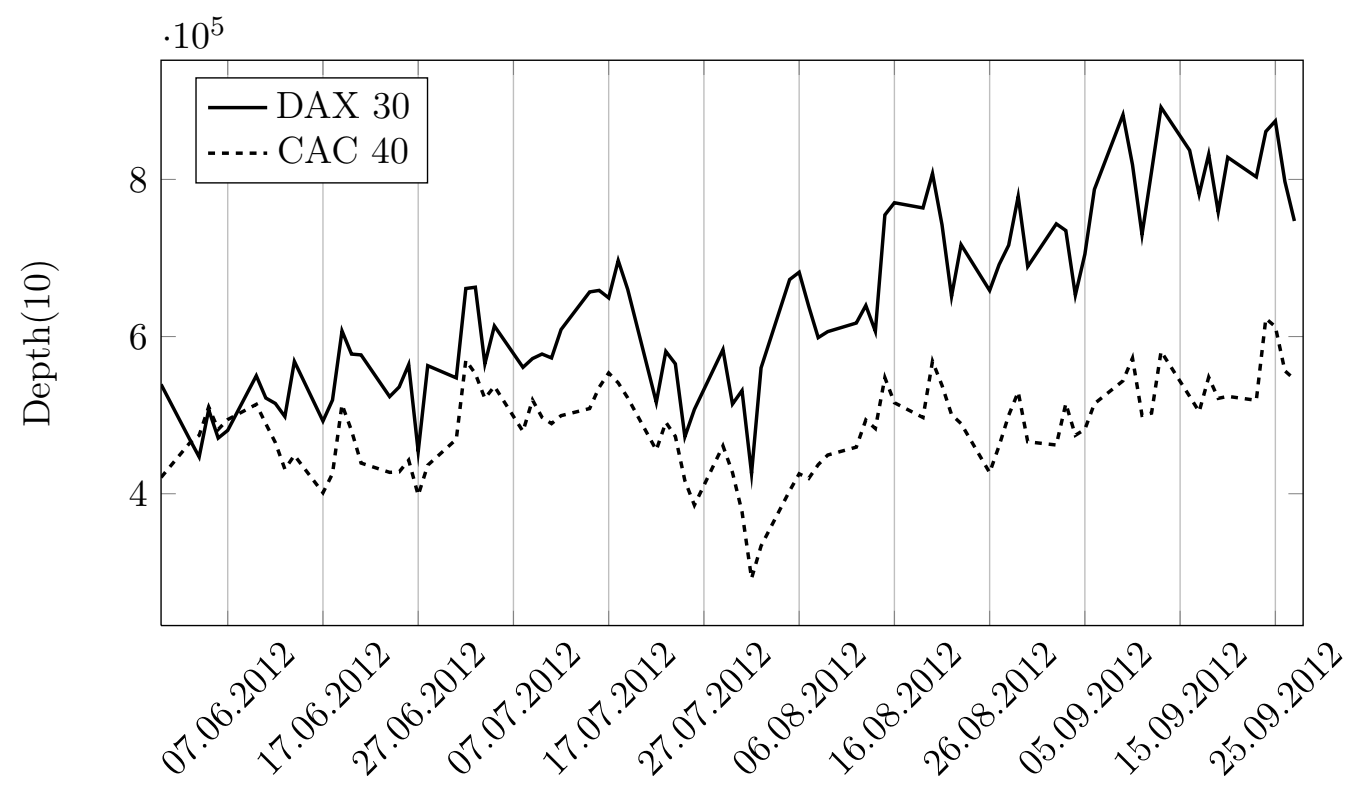

Figure 8. Depth(10) of the DAX and CAC 40 constituents (denoted in $€$ ).

Table 9: Order Book Depth Decomposition - Fixed Effects Regression (20 days)

\begin{tabular}{|c|c|c|c|c|c|c|c|c|c|}
\hline & & \multicolumn{4}{|c|}{$\operatorname{Depth}(5)$} & \multicolumn{4}{|c|}{$\operatorname{Depth}(5-10)$} \\
\hline & & \multicolumn{2}{|l|}{ no_contr } & \multicolumn{2}{|l|}{ contr } & \multicolumn{2}{|l|}{ no_contr } & \multicolumn{2}{|l|}{ contr } \\
\hline \multicolumn{10}{|c|}{ Market Capitalization Cluster } \\
\hline Change Q1 & $\begin{array}{l}\text { abs. } \\
\text { rel. }\end{array}$ & $\begin{array}{r}-53,961 \\
-19 \%\end{array}$ & $* * *$ & $\begin{array}{r}-83,836 \\
-30 \%\end{array}$ & $* * *$ & $\begin{array}{r}-66,987 \\
-14 \%\end{array}$ & $* *$ & $\begin{array}{r}-67,807 \\
-14 \%\end{array}$ & $* *$ \\
\hline Change Q2 & $\begin{array}{l}\text { abs. } \\
\text { rel. }\end{array}$ & $\begin{array}{r}-13,688 \\
-9 \%\end{array}$ & & $\begin{array}{r}-25,621 \\
-17 \%\end{array}$ & $*$ & $\begin{array}{r}-57,968 \\
-19 \%\end{array}$ & $* *$ & $\begin{array}{r}-38,699 \\
-13 \%\end{array}$ & \\
\hline Change Q3 & $\begin{array}{l}\text { abs. } \\
\text { rel. }\end{array}$ & $\begin{array}{r}-8,562 \\
-10 \%\end{array}$ & & $\begin{array}{r}-13,667 \\
-17 \%\end{array}$ & $* *$ & $\begin{array}{r}-22,627 \\
-15 \%\end{array}$ & $* *$ & $\begin{array}{r}-29,745 \\
-19 \%\end{array}$ & $* *$ \\
\hline \multicolumn{10}{|c|}{ Price Cluster } \\
\hline Change Q1 & $\begin{array}{l}\text { abs. } \\
\text { rel. }\end{array}$ & $\begin{array}{r}-59,657 \\
-22 \%\end{array}$ & $* * *$ & $\begin{array}{r}-81,529 \\
-30 \%\end{array}$ & $* * *$ & $\begin{array}{r}-91,875 \\
-22 \%\end{array}$ & $* * *$ & $\begin{array}{r}-56,244 \\
-13 \%\end{array}$ & $* *$ \\
\hline Change Q2 & $\begin{array}{l}\text { abs. } \\
\text { rel. }\end{array}$ & $\begin{array}{r}-17,328 \\
-11 \%\end{array}$ & * & $\begin{array}{r}-34,211 \\
-22 \%\end{array}$ & $* * *$ & $\begin{array}{r}-33,228 \\
-12 \%\end{array}$ & $* * *$ & $\begin{array}{r}-54,418 \\
-19 \%\end{array}$ & $* *$ \\
\hline Change Q3 & $\begin{array}{l}\text { abs. } \\
\text { rel. }\end{array}$ & $\begin{array}{r}-11,700 \\
-12 \%\end{array}$ & * & $\begin{array}{r}-13,442 \\
-14 \%\end{array}$ & & $\begin{array}{r}-36,654 \\
-17 \%\end{array}$ & $* *$ & $\begin{array}{r}-38,058 \\
-18 \%\end{array}$ & $* *$ \\
\hline
\end{tabular}

Aggregated FE regression results for the coefficient on the STT indicator and relative changes on the dependent variable Depth(5) and Depth(5-10) grouped by market capitalization as well as price thirds 10 trading days before and after August $1^{\mathrm{st}}$, 2012. Regressions are performed on the French subsample (no_contr) and together with the German subsample (contr). ***,** and * denote significance at the 1, 5 and 10 percent levels, respectively. 
Table 10: Order Book Depth Decomposition - Fixed Effects Regression (80 days)

\begin{tabular}{|c|c|c|c|c|c|c|c|c|c|}
\hline & & \multicolumn{4}{|c|}{ Depth 5} & \multicolumn{4}{|c|}{ Depth $(5-10)$} \\
\hline & & no_contr & & contr & & no_contr & & contr & \\
\hline \multicolumn{10}{|c|}{ Market Capitalization Cluster } \\
\hline Change Q1 & $\begin{array}{l}\text { abs. } \\
\text { rel. }\end{array}$ & $\begin{array}{r}-74,199 \\
-26 \%\end{array}$ & $* * *$ & $\begin{array}{r}-77,830 \\
-27 \%\end{array}$ & $* * *$ & $\begin{array}{r}-75,200 \\
-15 \%\end{array}$ & $* *$ & $\begin{array}{r}-93,036 \\
-19 \%\end{array}$ & $* * *$ \\
\hline Change Q2 & $\begin{array}{l}\text { abs. } \\
\text { rel. }\end{array}$ & $\begin{array}{r}-47,118 \\
-32 \%\end{array}$ & $* *$ & $\begin{array}{r}-27,104 \\
-18 \%\end{array}$ & & $\begin{array}{r}-51,404 \\
-18 \%\end{array}$ & $* *$ & $\begin{array}{r}-100,864 \\
-35 \%\end{array}$ & $* *$ \\
\hline Change Q3 & $\begin{array}{r}\text { abs. } \\
\text { rel. }\end{array}$ & $\begin{array}{r}-15,424 \\
-18 \%\end{array}$ & $* * *$ & $\begin{array}{r}-21,082 \\
-25 \%\end{array}$ & $* *$ & $\begin{array}{r}-9,232 \\
-6 \%\end{array}$ & & $\begin{array}{r}-73,112 \\
-48 \%\end{array}$ & $* * *$ \\
\hline \multicolumn{10}{|c|}{ Price Cluster } \\
\hline Change Q1 & $\begin{array}{l}\text { abs. } \\
\text { rel. }\end{array}$ & $\begin{array}{r}-97,180 \\
-38 \%\end{array}$ & $* * *$ & $\begin{array}{r}-59,344 \\
-28 \%\end{array}$ & $* *$ & $\begin{array}{r}-90,503 \\
-22 \%\end{array}$ & $* * *$ & $\begin{array}{r}-69,802 \\
-17 \%\end{array}$ & $* *$ \\
\hline Change Q2 & $\begin{array}{l}\text { abs. } \\
\text { rel. }\end{array}$ & $\begin{array}{r}-44,757 \\
-28 \%\end{array}$ & $* *$ & $\begin{array}{r}-31,120 \\
-19 \%\end{array}$ & $* *$ & $\begin{array}{r}-49,250 \\
-16 \%\end{array}$ & $* *$ & $\begin{array}{r}-100,286 \\
-33 \%\end{array}$ & $* * *$ \\
\hline Change Q3 & $\begin{array}{l}\text { abs. } \\
\text { rel. }\end{array}$ & $\begin{array}{r}-14,973 \\
-15 \%\end{array}$ & $* *$ & $\begin{array}{r}-25,465 \\
-25 \%\end{array}$ & $*$ & $\begin{array}{r}-26,285 \\
-12 \%\end{array}$ & $* * *$ & $\begin{array}{r}-78,047 \\
-36 \%\end{array}$ & $* * *$ \\
\hline
\end{tabular}

Aggregated FE regression results for the coefficient on the STT indicator and relative changes on the dependent variable Depth(5) and Depth(5-10) grouped by market capitalization as well as price thirds 40 trading days before and after August $1^{\mathrm{st}}$, 2012. Regressions are performed on the French subsample (no_contr) and together with the German subsample (contr). ***,** and * denote significance at the 1, 5 and 10 percent levels, respectively.

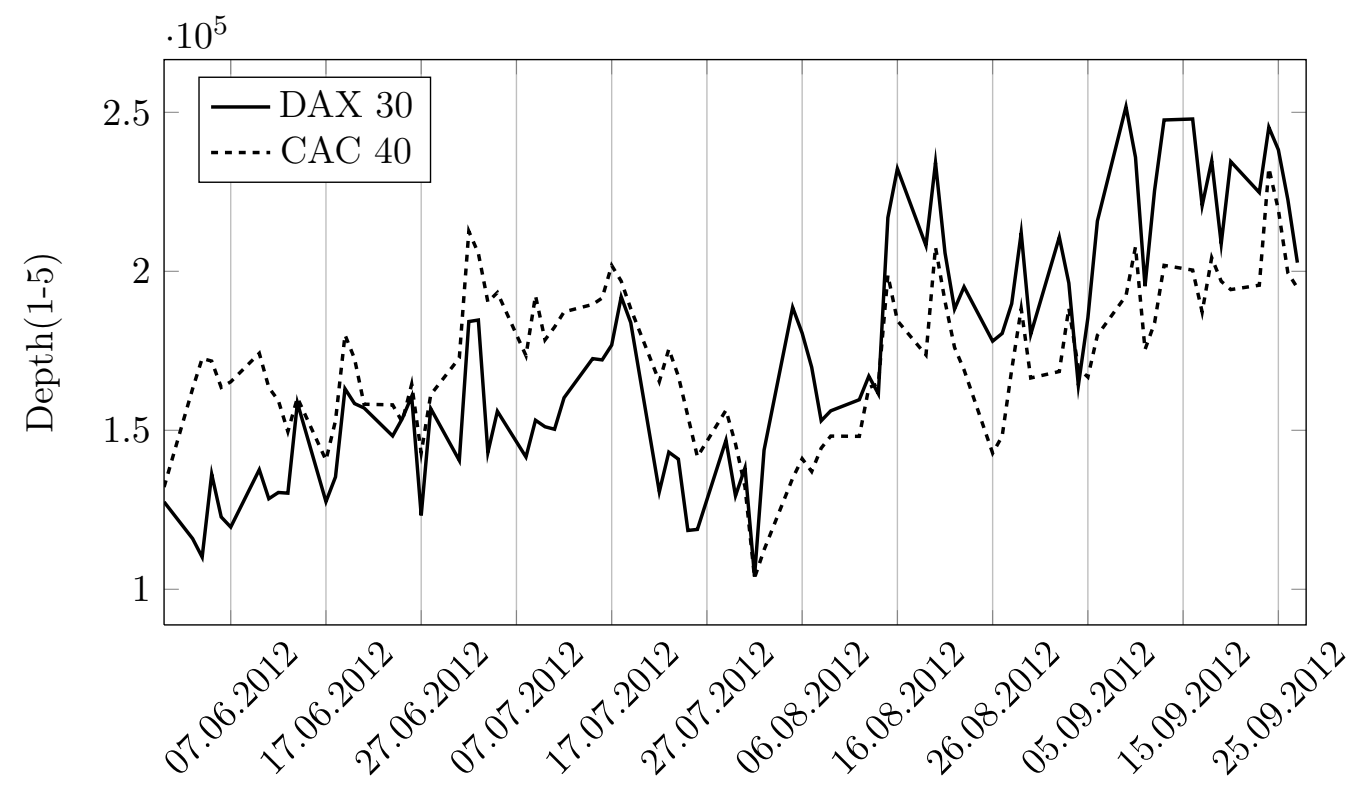

Figure 9. Depth(5) of the DAX and CAC 40 constituents (denoted in $€$ ). 


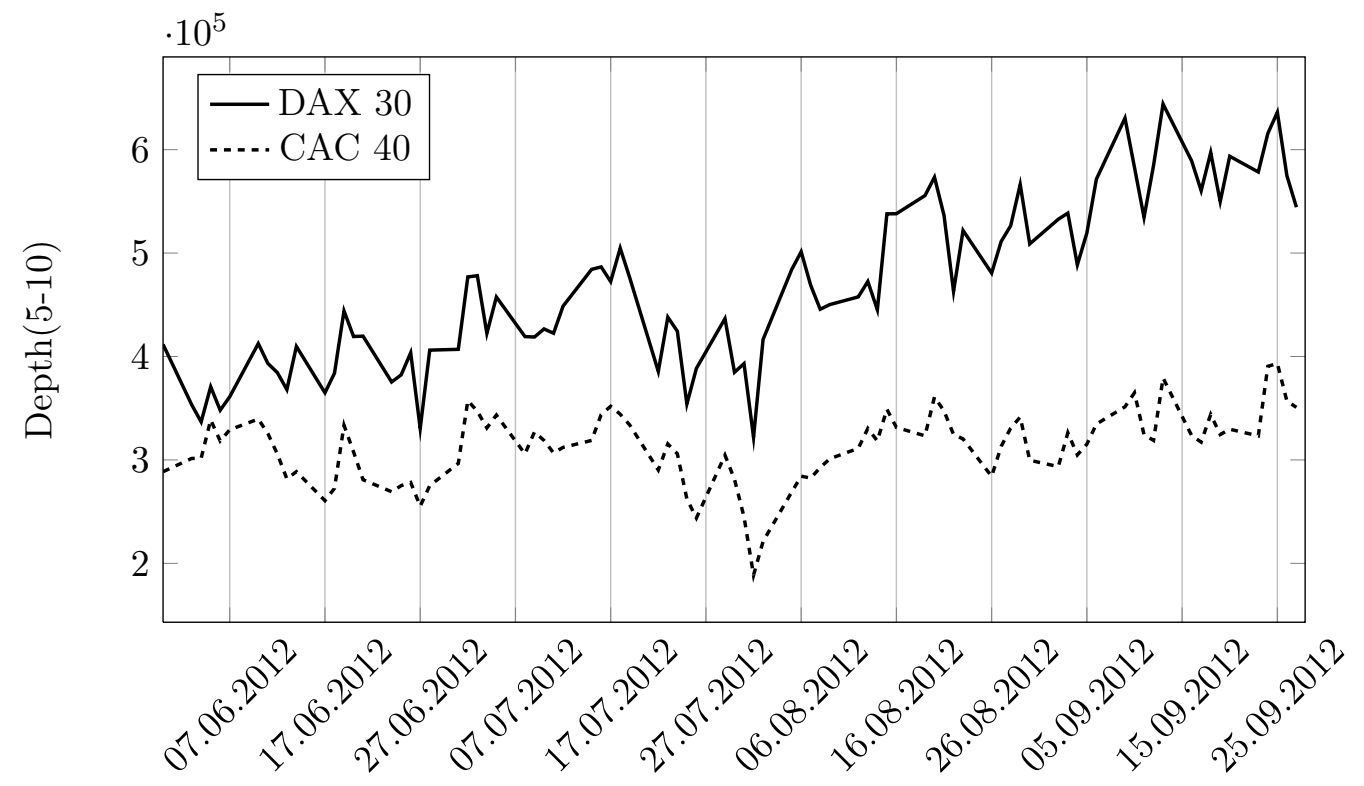

Figure 10. Depth(5-10) of the DAX and CAC 40 constituents (denoted in $€$ ). 


\section{The Effect on Inter-Market Price Coordination}

Following L. Harris (2003), prices in securities markets contain valuable signals supporting the direction of resources and cash flows to their most highly valued destinies. Within the European securities markets system, the fragmentation of order flow yields a unique characteristic to study the effect of STTs on inter-market information transmission as price dispersion is an important indicator for fragmented securities market's quality. Derived from the law of one price, "frictionless" markets will price homogeneous goods uniformly, i.e. show zero price dispersion. Within securities markets this becomes apparent as perfect identical equity instruments are listed on various markets due to the increased fragmentation of the order flow. Therefore, French blue chips can additionally be traded on several Multilateral Trading Facilities, Systematic Internalisers or on Overthe-Counter markets. However, asymmetric information diffusion as well as difference in search costs may result in temporal price dispersion (Lamont \& Thaler, 2003). Due to the prevailing pervasion of fully automated, low-latency trading strategies electronically traded stock price homogeneity has dramatically increased as news are incorporated more accurate and market monitoring and subsequent arbitrage opportunities become more apparent (Martinez \& Rosu, 2011; Hendershott \& Riordan, 2011; Gomber et al., 2011).

This development has increased price integrity and investor's certainty to trade on fully incorporated prices. However, the introduction of a STT may reverse this development as a certain amount of price-adjusting, low-revenue trades will become unprofitable and therefore disappear as suggested by Culp (2010). As such, STTs may discourage certain financial transactions that reduce a market's informational efficiency due to the higher transaction costs. Hence, temporal price dispersion between markets may increase in order to become profitable again, leading to an average higher price dispersion and a deterioration of the price equilibrium relationship. We show that this phenomenon occurs to a significant and verifiable amount due to the introduction of the French STT. We will bring up indications that first, price heterogeneity of French stocks which are traded simultaneously on different venues has increased and second, that the price equilibrium adjustment mechanism, that is the rate of reversion toward the price equilibrium relationship after price shocks, has been significantly weakened due to the introduction of the French STT.

In order to empirically analyze this process we again rely on stock market data of the French blue chip index CAC 40. Through to the harmonization of the European securities market system initiated by the Markets in Financial Instruments Directive (MiFID) in 2007 French stocks, among others, are traded simultaneously on various venues. According to Fidessa (2012), the magnitude of CAC 40 stocks are executed on NYSE Euronext Paris (NY) as well as Chi-X's CXE MTF (Chi). Together, both account for about $85 \%$ of all European traded volume. We analyze price co-movement on these two dominant venues using an event-based approach. Further we investigate the impact on the equilibrium correction mechanism using a co-integration framework suggested by Engle and Granger (1987). Again, we rely on tick by tick data provided by Thomson Reuters Datascope Tick History service. Theoretically, comparing stock prices among venues requires event synchrony as well as homogeneity in liquidity and transaction costs. Since trades as well as order book updates may occur asynchronously on both markets, we rely on a form of aggregation. In order to achieve event synchrony this analysis is based on the one minute average price on both trading venues. This form of aggregation is not very stringent since we do not measure the absolute amount of price dispersion but only the change through the introduction of the STT. This further applies for different 
levels of transaction costs as this comparison is only based on the difference to the pre-STT level. However, we control for asymmetries in liquidity within each respective second, since asynchronous liquidity levels on both market will be a major source of price dispersion. We rely on the 36 of the CAC 40 stocks introduced in the previous chapter. Due to data unavailability on Chi-X we have to dismiss one instrument. Within the preand post event window of 40 days, the minute-wise aggregation leads to a huge amount of observations per instrument. We therefore focus on stock-wise time series regressions to account for the long time series.

To estimate price dispersion, we rely on the absolute per-minute price differences which is based on the following rational. Derived from the law of one price, within frictionless markets, differences in explicit transaction costs will be reflected in a persistent difference in prices among venues. Therefore, a systematic change in the transaction costs, like introduced by the French STT, should have no impact on the per-minute price differences as both venues are affected equally. However, temporal asymmetries in information and liquidity will appear as one-sided shocks that will be reproduced at the other market immediately if arbitrage opportunities are exploited effectively. However, if the STT discourages such transactions, temporal price dispersion must further increase in order to become profitable again. If this is apparent, we will observe a statistic significant increase in the per-minute price differences. We utilize an autoregressive distributed lag (ADL) model to account for additional sources of price heterogeneity of the close history of each control variable as well as within the dependent variable. To further include the before mentioned alternative sources of price dispersion, we control for the comprehensive liquidity level as well as liquidity asynchrony on both markets via the formula (5).

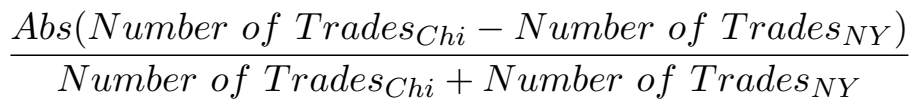

Thereby, if one market shows excessive trading activity, while the other market does not, we penalize the respective time interval with a high asynchrony value. If both markets show similar activity the equation (5) equals zero. In addition, we include ten lags (ten minutes) of each variable to control for time persistent effects that may influence future observations. The event effect is modeled as dummy variable, becoming 1 after the introduction of the French STT. A significant positive coefficient at the event dummy will indicate an increase in the mean per-minute differences. All variables are tested for stationary following the adjusted Dickey-Fuller approach as proposed by Dickey and Fuller (1979) (results omitted). We adjust standard errors as shown by Newey and West (1987) to account for remaining autocorrelation as well as heteroscedasticity. Since the regression is performed stock by stock, we report the results stock-wise and look for index tendencies.

Table 11 aggregates the coefficients on the STT dummy as well as respective tstatistics of our approach. Again, as the French STT taxes trading on both markets, the persistent level of price dispersion should remain the same, if arbitrage opportunities are exploited effectively. The results show that the coefficient at the STT dummy is significantly positive throughout most instruments (26 out of 35 instruments); we observe a decrease in price homogeneity, i.e. decreasing inter-market information transmission after the introduction of the STT. Relatively to the average absolute price dispersion (the constant) prior to the STT, inter-market price coordination has decreased by $20 \%$ on average. Not depicted in the table but statistically significant in each regression are our control variables, the comprehensive liquidity level as well as liquidity asynchrony 
Table 11: Price Homogeneity after the STT - Time Series Regression Results

\begin{tabular}{|c|c|c|c|}
\hline & Coefficient on STT indicator & t-value & \\
\hline ACCP.PA & 0.0000 & 0.54 & \\
\hline AIRP.PA & 0.0009 & 6.68 & $* * *$ \\
\hline ALSO.PA & 0.0005 & 5.57 & $* * *$ \\
\hline ALUA.PA & 0.0000 & -6.73 & $* * *$ \\
\hline AXAF.PA & 0.0003 & 14.14 & $* * *$ \\
\hline BNPP.PA & 0.0005 & 9.46 & $* * *$ \\
\hline BOUY.PA & 0.0000 & -0.03 & \\
\hline CAGR.PA & 0.0001 & 7.77 & $* * *$ \\
\hline CAPP.PA & -0.0001 & -0.52 & \\
\hline CARR.PA & 0.0003 & 8.33 & $* * *$ \\
\hline DANO.PA & -0.0003 & -4.66 & $* * *$ \\
\hline EDF.PA & 0.0003 & 4.14 & $* * *$ \\
\hline ESSI.PA & 0.0007 & 5.34 & $* * *$ \\
\hline FTE.PA & 0.0001 & 3.44 & $* * *$ \\
\hline GSZ.PA & 0.0001 & 3.19 & $* * *$ \\
\hline LAFP.PA & 0.0008 & 7.92 & $* * *$ \\
\hline LVMH.PA & 0.0004 & 1.66 & $*$ \\
\hline MICP.PA & 0.0008 & 5.33 & $* * *$ \\
\hline OREP.PA & 0.0017 & 9.33 & $* * *$ \\
\hline PERP.PA & 0.0009 & 6.9 & $* * *$ \\
\hline PRTP.PA & 0.0007 & 1.87 & $*$ \\
\hline PUBP.PA & 0.0004 & 5.09 & $* * *$ \\
\hline RENA.PA & 0.0002 & 2.41 & $* *$ \\
\hline SASY.PA & 0.0006 & 9.72 & $* * *$ \\
\hline SCHN.PA & 0.0006 & 7.87 & $* * *$ \\
\hline SEVI.PA & 0.0003 & 7.59 & $* * *$ \\
\hline SGEF.PA & 0.0003 & 3.92 & $* * *$ \\
\hline SGOB.PA & -0.0001 & -0.76 & \\
\hline SOGN.PA & 0.0002 & 5.42 & $* * *$ \\
\hline TECF.PA & -0.0001 & -0.33 & \\
\hline TOTF.PA & 0.0002 & 6.83 & $* * *$ \\
\hline UNBP.PA & 0.0005 & 1.58 & \\
\hline VIE.PA & 0.0000 & 0.84 & \\
\hline VIV.PA & 0.0004 & 10.58 & $* * *$ \\
\hline VLLP.PA & 0.0013 & 11.19 & $* * *$ \\
\hline
\end{tabular}

Aggregated time series regression results for the coefficient on the STT indicator on the absolute return of the per-minute price differences between the Euronext Paris and Chi-X Europe trading venue. ***, ** and * denote significance at the 1,5 and 10 percent levels, respectively. 
show further deteriorating effects on price dispersion besides the tax effect. However, two instruments show significant lower price dispersion after the tax and up to now, we only rely on the analysis of the French instruments. Therefore, this effect could also be catalyzed by ommitted effects like the prevailing European debt crisis and not origin from the introduction of the French STT. To control for these omitted effects we apply the proposed approach on the constituents of the German DAX 30 index. However, as we rely on a instrument-wise time series regression within this approach, direct comparability becomes non-trivial. As the quality of inter-market price transmission is directly affected by the degree of order flow fragmentation of every instrument in every observation period, benchmark and treatment index should again exhibit similar degrees of fragmentation. According to Fidessa (2012) Deutsche Boerse (NYSE Euronexr Paris) accounts for $65 \%$ (61\%) market share of the DAX 30 index (CAC 40 index) while Chi-X CXE accounts for $20 \%$ (21\%) off all traded volume. As these market shares remain steady throughout our observation period, we can be assure that no sudden changes within the volume distribution on each venue will bias our inter-market measures. Nevertheless, a direct instrument by instrument comparison is unappropriate since we can not rely on instrument matching. We therefore analyze our results in respect on a market-wise tendency. Table 12 aggregates the results for price dispersion of the DAX 30 instruments.

8 out of 30 DAX instruments show a significant increase in price dispersion after the introduction of the French STT. However, the same amount of instruments show a respective decrease, where the rest remains insignificant throughout the observations period. Such diverting results within both indices indicate systematic different developments among treatment and control sample and provide indication for a causality between the deterioration in price homogeneity and the introduction of the STT. If price dispersion must increase in order to become profitable again for arbitrageurs, price information efficiency is impeded and may result in suboptimal capital allocation. However, a greater threat to a fragmented liquidity system may result if not only prices drift further apart but simultaneously the rate of reversion toward the price equilibrium relationship is significantly weakened. We address this follow-up question within a modified approach. Our methodology is based on co-integrated time series as shown by Engle and Granger (1987) who studied the equilibrium relationships of a closely related pair of time series which are forced to move in synchrony, i.e. which are co-integrated. The authors show that under the presumption of co-integration, an error correction model (ECM) can be built that describes the dynamic long-run and short-run behavior of the underlying pair of time series. This ECM links the long-run equilibrium relationship of the non-stationary relationship -implied by the traditional OLS estimation- with the short-run dynamic adjustment that describes how the variables react when they move out of their long-run equilibrium (Engle \& Granger, 1987). We apply this approach to analyze the impact of the French STT on the short-term error correction adjustment and show that since the introduction of the STT this adjustment mechanism has severely deteriorated, as temporal dispersions of the long-run equilibrium consume additional time to be fully restored. This supports our assumption that not only price homogeneity has deteriorated but the decline of trading activity has further weakened information dissemination and transmission between markets.

According to Engle and Granger (1987) two time series are considered to be cointegrated if a linear combination exists which is stationary $(\mathrm{I}(0))$. This linear combination, if unknown, can be estimated by a simple regression relationship, where the residual term captures all deviations from the equilibrium state. The intuition behind this augmentation is that I(1) time series with a long-run equilibrium relationship like 
Table 12: Price Homogeneity after the STT - Time Series Regression Results

\begin{tabular}{|c|c|c|c|}
\hline & Coefficient on STT indicator & t-value & \\
\hline ADSGn.DE & -0.0001 & -0.78 & \\
\hline ALVG.DE & -0.0001 & -0.8 & \\
\hline BASFn.DE & 0.0000 & 0.06 & \\
\hline BAYGn.DE & 0.0002 & 3.65 & $* * *$ \\
\hline BEIG.DE & 0.0006 & 5.92 & $* * *$ \\
\hline BMWG.DE & -0.0005 & -4.86 & $* * *$ \\
\hline CBKG.DE & 0.0000 & -0.62 & \\
\hline CONG.DE & -0.0010 & -5.03 & $* * *$ \\
\hline DAIGn.DE & -0.0001 & -0.95 & \\
\hline DB1Gn.DE & 0.0000 & 0.39 & \\
\hline DBKGn.DE & 0.0000 & 0.28 & \\
\hline DPWGn.DE & -0.0001 & -4.99 & $* * *$ \\
\hline DTEGn.DE & 0.0001 & 6.26 & $* * *$ \\
\hline EONGn.DE & 0.0001 & 4.95 & $* * *$ \\
\hline FMEG.DE & -0.0007 & -7.07 & $* * *$ \\
\hline FREG.DE & 0.0003 & 1.91 & $*$ \\
\hline HEIG.DE & -0.0005 & -5.19 & $* * *$ \\
\hline HNKG_p.DE & 0.0000 & -0.47 & \\
\hline IFXGn.DE & -0.0001 & -2.01 & $* *$ \\
\hline LHAG.DE & 0.0003 & 9.9 & $* * *$ \\
\hline LING.DE & 0.0000 & -0.04 & \\
\hline LXSG.DE & -0.0009 & -5.96 & $* * *$ \\
\hline MRCG.DE & -0.0004 & -2.38 & $* *$ \\
\hline MUVGn.DE & 0.0024 & 10.88 & $* * *$ \\
\hline RWEG.DE & -0.0001 & -0.95 & \\
\hline SAPG.DE & 0.0006 & 4.05 & $* * *$ \\
\hline SDFGn.DE & -0.0001 & -1.71 & $*$ \\
\hline SIEGn.DE & 0.0001 & 0.67 & \\
\hline TKAG.DE & 0.0004 & 10.52 & $* * *$ \\
\hline VOWG_p.DE & 0.0001 & 0.31 & \\
\hline
\end{tabular}

Aggregated time series regression results for the coefficient on the STT indicator on the absolute return of the per-minute price differences between the German Xetra and Chi-X Europe trading venue. ***, ** and * denote significance at the 1, 5 and 10 percent levels, respectively. 
above, cannot drift too far apart from each other so the subsequent residual term should be stationary or $\mathrm{I}(0)$. In this situation temporal shocks to the equilibrium state, i.e., the residuals, will be reverted over time and the equilibrium state will be continually be restored. Additionally, the speed of this mean reverting mechanism could be estimated as coefficient on the lagged residual term within the short-run regression relationship (Engle \& Granger, 1987). We will show that this speed of adjustment deteriorates in the presence of the STT. We continue on the following approach: First, we show that the 1 minute average prices on NYSE Euronext and Chi-X are both I(1). That is:

$$
\epsilon_{t}=P_{t, N Y}-P_{t, C h i} \text { is } I(0)
$$

Second, as proposed by Engle and Granger (1987) we estimate the ECM in the following way:

$$
\begin{aligned}
\triangle P_{t, N Y}=\delta+\Delta & P_{t, C h i}+E C T\left(P_{t-1, N Y}-P_{t-1, C h i}\right)+I_{t,\{0,1\}} \\
& +E C T\left(P_{t-1, N Y}-P_{t-1, C h i}\right) * I_{t,\{0,1\}}+\Theta_{t}
\end{aligned}
$$

Where $P_{t, N Y}$ is the 1 minute average price on NYSE Euronext, respective $P_{t, C h i}$ on Chi-X, triangle indicates differenced values and $E C T\left(P_{t-1, N Y}-P_{t-1, C h i}\right)$ the error correction term (ECT), i.e. speed of adjustment as proposed by Engle and Granger (1987). Further, in order to capture a possible structural break in the speed of adjustment we include an event-dummy $I_{t,\{0,1\}}$, that changes the value to one after August $1^{\text {st }}$, as well as the interaction with the error correction term. The coefficient on $E C T\left(P_{t-1, N Y}-P_{t-1, C h i}\right) * I_{t,\{0,1\}}$ yields the effect of the French SST on the speed of adjustment, i.e. the interaction between the event dummy and the ECT. Table 13 aggregates the result of the stock-wise estimation. Stationarity of estimation (5) is tested by adjusted Dickey-Fuller test (no constant) and Phillips-Perron test (10 Lags, not reported) as proposed by Engle and Granger (1987). Durbin's alternative test and BreuschPagan's test shows instrument-wise presents of autocorrelation and heteroscedasticity subsequently we use robust standard errors in (7). Table 13 aggregates the stock-wise results on the proposed methodology. We depict stationary tests for equation (6) as well as the coefficients on $E C T\left(P_{t-1, N Y}-P_{t-1, C h i}\right)$ and $E C T\left(P_{t-1, N Y}-P_{t-1, C h i}\right) * I_{t,\{0,1\}}$.

Adjusted Dickey-Fuller test indicates $\mathrm{I}(0)$ of the linear combination within all instruments as depicted in the left row of Table 13. The Coefficient on $\operatorname{ECT}\left(P_{t-1, N Y}-\right.$ $\left.P_{t-1, C h i}\right)$ is statistically significant among all analyzed stocks, indicating that any form of price disequilibrium between NYSE and Chi-X is reverted by $73 \%$ on average within the following minute. This result is not surprising, as co-integration within securities prices could empirically be shown by various studies like F. d. Harris, McInish, Shoesmith, and Wood (1995) and F. d. Harris, McInish, and Wood (2002). However, the coefficient at the interaction term $\operatorname{ECT}\left(P_{t-1, N Y}-P_{t-1, C h i}\right) * I_{t,\{0,1\}}$ is statistically significant and opposing the ECT's sign in almost all instruments. Henceforth, these findings suggest that the introduction of the French STT has deteriorated the speed of adjustment towards the long-run price equilibrium relationship leading to extended price dispersion between co-listed stocks (together $E C T\left(P_{t-1, N Y}-P_{t-1, C h i}\right)+E C T\left(P_{t-1, N Y}-P_{t-1, C h i}\right) * I_{t,\{0,1\}}$. Following the argumentation of Habermeier and Kirilenko (2001), inter-market information efficiency has decreased as the information transmission process between markets has been signficiantly weakened. Again, as we so far focused on French instruments alone, robustness is not given as such effect could also be originated by the macro-economic development of the European trading system. Table 14 therefore aggregates stock-wise results on the DAX 30 sample. 
Table 13: Engle and Granger Co-Integration Approach and Error Correction Results for CAC 40

\begin{tabular}{|c|c|c|c|c|c|c|c|}
\hline & adj Dickey Fuller & $\mathrm{ECT}$ & t-value & & ECT*Flag & t-value & \\
\hline ACCP.PA & -59.15 & -0.59 & -28.85 & $* * *$ & 0.13 & 4.61 & $* * *$ \\
\hline AIRP.PA & -60.55 & -0.79 & -54.54 & $* * *$ & 0.12 & 3.66 & $* * *$ \\
\hline ALSO.PA & -60.80 & -0.68 & -19.49 & $* * *$ & 0.11 & 2.55 & $* *$ \\
\hline ALUA.PA & -57.00 & -0.71 & -15.29 & $* * *$ & 0.09 & 1.93 & $*$ \\
\hline AXAF.PA & -59.91 & -0.89 & -77.88 & $* * *$ & 0.06 & 2.75 & $* * *$ \\
\hline BNPP.PA & -58.68 & -0.97 & -128.41 & $* * *$ & 0.01 & 0.53 & \\
\hline BOUY.PA & -64.62 & -0.56 & -17.07 & $* * *$ & 0.03 & 0.73 & \\
\hline CAGR.PA & -60.62 & -0.86 & -33.37 & $* * *$ & -0.03 & -1.29 & \\
\hline CAPP.PA & -65.68 & -0.54 & -2.95 & $* * *$ & 0.02 & 0.09 & \\
\hline CARR.PA & -57.57 & -0.77 & -60.08 & $* * *$ & 0.04 & 2.11 & $* *$ \\
\hline DANO.PA & -57.78 & -0.87 & -73.50 & $* * *$ & 0.01 & 0.44 & \\
\hline EDF.PA & -60.00 & -0.58 & -11.68 & $* * *$ & 0.08 & 1.64 & $*$ \\
\hline ESSI.PA & -59.60 & -0.73 & -40.67 & $* * *$ & 0.11 & 4.69 & $* * *$ \\
\hline FTE.PA & -55.70 & -0.73 & -13.62 & $* * *$ & 0.00 & 0.00 & \\
\hline GSZ.PA & -57.86 & -0.80 & -60.89 & $* * *$ & 0.04 & 1.81 & * \\
\hline LAFP.PA & -63.44 & -0.65 & -19.75 & $* * *$ & 0.15 & 2.50 & $* *$ \\
\hline LVMH.PA & -57.49 & -0.65 & -17.07 & $* * *$ & -0.06 & -1.43 & \\
\hline MICP.PA & -64.46 & -0.65 & -8.71 & $* * *$ & 0.03 & 0.41 & \\
\hline OREP.PA & -55.41 & -0.78 & -47.32 & $* * *$ & 0.24 & 5.83 & $* * *$ \\
\hline PRTP.PA & -57.28 & -0.73 & -50.95 & $* * *$ & 0.07 & 3.29 & $* * *$ \\
\hline PUBP.PA & -57.32 & -0.47 & -7.87 & $* * *$ & 0.04 & 0.71 & \\
\hline PERP.PA & -60.00 & -0.66 & -21.81 & $* * *$ & 0.06 & 1.64 & * \\
\hline RENA.PA & -59.50 & -0.81 & -36.46 & $* * *$ & 0.08 & 2.81 & $* * *$ \\
\hline SASY.PA & -56.64 & -0.88 & -94.87 & $* * *$ & 0.00 & 0.32 & \\
\hline SCHN.PA & -63.00 & -0.86 & -49.85 & $* * *$ & 0.03 & 0.83 & \\
\hline SEVI.PA & -60.88 & -0.46 & -14.04 & $* * *$ & 0.12 & 2.96 & $* * *$ \\
\hline SGEF.PA & -60.20 & -0.79 & -30.46 & $* * *$ & 0.08 & 1.86 & $* *$ \\
\hline SGOB.PA & -61.32 & -0.81 & -23.25 & $* * *$ & 0.05 & 0.94 & \\
\hline SOGN.PA & -60.30 & -0.92 & -101.41 & $* * *$ & 0.03 & 1.97 & $* *$ \\
\hline TECF.PA & -62.61 & -0.74 & -42.99 & $* * *$ & 0.15 & 5.08 & $* * *$ \\
\hline TOTF.PA & -57.24 & -0.94 & -84.36 & $* * *$ & 0.03 & 7.79 & $* * *$ \\
\hline UNBP.PA & -56.24 & -0.58 & -43.71 & $* * *$ & 0.07 & 4.05 & $* * *$ \\
\hline VIE.PA & -59.70 & -0.75 & -27.79 & $* * *$ & 0.10 & 3.15 & $* * *$ \\
\hline VIV.PA & -57.45 & -0.74 & -19.51 & $* * *$ & 0.05 & 1.11 & \\
\hline VLLP.PA & -61.63 & -0.68 & -13.66 & $* * *$ & 0.15 & 2.70 & $* * *$ \\
\hline
\end{tabular}

Aggregated Engle and Granger co-integrated time series results modified in formula (7) for the 35 CAC 40 instruments. Minute-wise price averages for NYSE Euronext and Chi-X with intraday auctions excluded. Stationary for each instrument is tested by adjusted Dickey-Fuller test (no constant) as well as PhillipsPerron test (10 Lags, not reported). Error correction representation for the coefficient on $E C T\left(P_{t-1, N Y}-\right.$ $\left.P_{t-1, C h i}\right)$ as well as respective t-value. Interaction term $E C T\left(P_{t-1, N Y}-P_{t-1, C h i}\right) * I_{t},\{0,1\}$ represents changes in the error correction term after the French $S T T$ with respective t-values. ***, ** and * denote significance at the 1,5 and 10 percent levels, respectively. 
Table 14: Engle and Granger Co-Integration Approach and Error Correction Results for DAX 30

\begin{tabular}{|c|c|c|c|c|c|c|c|}
\hline & adj Dickey Fuller & ECT & t-value & & ECT*Flag & t-value & \\
\hline ADSGn.DE & -60.50 & -0.77 & -37.23 & $* * *$ & 0.04 & 0.49 & \\
\hline ALVG.DE & -59.86 & -0.87 & -33.79 & $* * *$ & 0.14 & 1.60 & \\
\hline BASFn.DE & -58.93 & -0.85 & - 18.67 & $* * *$ & 0.07 & 0.66 & \\
\hline BAYGn.DE & -60.82 & -0.96 & -46.61 & $* * *$ & 0.16 & 3.22 & $* * *$ \\
\hline BEIG.DE & - 60.79 & -0.57 & -18.52 & $* * *$ & -0.01 & -0.35 & \\
\hline BMWG.DE & -61.10 & -0.94 & -40.02 & $* * *$ & 0.06 & 0.81 & \\
\hline CBKG.DE & - 59.79 & -0.68 & -13.56 & $* * *$ & -0.01 & -0.10 & \\
\hline CONG.DE & -65.04 & -0.67 & -7.01 & $* * *$ & -0.03 & -0.26 & \\
\hline DAIGn.DE & -58.21 & -0.86 & -28.32 & $* * *$ & 0.09 & 1.21 & \\
\hline DB1Gn.DE & -60.41 & -0.69 & -21.95 & $* * *$ & 0.01 & 0.15 & \\
\hline DBKGn.DE & -60.41 & -0.88 & -13.68 & $* * *$ & 0.06 & 0.50 & \\
\hline DPWGn.DE & -60.99 & -0.57 & -11.46 & $* * *$ & -0.33 & -5.66 & $* * *$ \\
\hline DTEGn.DE & -59.41 & -0.92 & -32.39 & $* * *$ & 0.05 & 1.38 & \\
\hline EONGn.DE & -58.72 & -0.80 & -7.77 & $* * *$ & 0.03 & 0.24 & \\
\hline FMEG.DE & -60.39 & -0.66 & -17.30 & $* * *$ & 0.01 & 0.21 & \\
\hline FREG.DE & -63.26 & -0.79 & -23.06 & $* * *$ & 0.16 & 3.28 & $* * *$ \\
\hline HEIG.DE & -61.65 & -0.77 & -38.59 & $* * *$ & 0.05 & 1.68 & \\
\hline HNKGp.DE & -61.07 & -0.74 & - 19.43 & $* * *$ & 0.04 & 0.85 & \\
\hline IFXGn.DE & -60.96 & -0.82 & -27.06 & $* * *$ & 0.02 & 0.19 & \\
\hline LHAG.DE & -62.46 & -0.51 & -4.19 & $* * *$ & 0.03 & 0.24 & \\
\hline LING.DE & -56.15 & -0.89 & -13.52 & $* * *$ & 0.21 & 2.50 & $* *$ \\
\hline LXSG.DE & -59.07 & -0.82 & -22.10 & $* * *$ & 0.12 & 1.63 & \\
\hline MRCG.DE & -59.74 & -0.66 & -17.83 & $* * *$ & 0.05 & 1.14 & \\
\hline MUVGn.DE & -56.26 & -0.77 & -29.36 & $* * *$ & 0.10 & 2.56 & $* *$ \\
\hline RWEG.DE & -60.13 & -0.83 & -31.16 & $* * *$ & 0.08 & 1.47 & \\
\hline SAPG.DE & -58.39 & -0.94 & -25.94 & $* * *$ & 0.41 & 3.39 & $* * *$ \\
\hline SDFGn.DE & -62.91 & -0.60 & -7.17 & $* * *$ & 0.00 & 0.02 & \\
\hline SIEGn.DE & -60.36 & -0.86 & -26.39 & $* * *$ & 0.18 & 0.84 & \\
\hline TKAG.DE & -60.18 & -0.76 & -16.80 & $* * *$ & -0.02 & -0.16 & \\
\hline VOWGp.DE & -58.71 & -0.88 & -21.32 & $* * *$ & 0.08 & 1.20 & \\
\hline
\end{tabular}

Aggregated Engle and Granger co-integrated time series results modified in formula (7) for the all DAX 30 instruments. Minute-wise price averages for Deutsche Boerse Xetra and Chi-X with intraday auctions excluded. Stationary for each instrument is tested by adjusted Dickey-Fuller test (no constant) as well as Phillips-Perron test (10 Lags, not reported). Error correction representation for the coefficient on $\operatorname{ECT}\left(P_{t-1, N Y}-\alpha-P_{t-1, C h i}\right)$ as well as respective t-value. Interaction term $\operatorname{ECT}\left(P_{t-1, N Y}-\alpha-\right.$ $\left.P_{t-1, C h i}\right) * I_{t,\{0,1\}}$ represents changes in the error correction term after the French $S T T$ with respective t-values. ***,** and $*$ denote significance at the 1,5 and 10 percent levels, respectively. 
Comparable to the French subsample all instrument's price show a close equilibrium relationships considering the $\mathrm{I}(0)$ residuals of the prices' linear combination. Even within the coefficient on ECT, the results indicate that likewise the French stocks, shocks to the equilibrium relationships are reverted by $78 \%$ on average within the following minute. However, by focusing on the event-based interaction term $E C T\left(P_{t-1, N Y}-P_{t-1, C h i}\right) * I_{t,\{0,1\}}$ only 5 out of 30 instruments show an significant deterioration in the error correction term after 1st August, 2012. Due to the strong diveregence within the German and French sample, we can conculde that this effects is at least partly initiated through the impementation of the STT. 


\section{Conclusion}

The introduction of the French STT marks an extraordinary resolution to regulate and temper the financial system in the face of the recent financial crisis. Great effort has been spent to spare market efficiency, hinder regulatory arbitrage and dampen predatory activities. Still, the applicability of the French proposition as well as the general concept of a STT is controversially discussed among academics and politicians. The theoretical research is quite advanced while the empirical guidance is still scarce as of 2012 STTs are still non-common. Foremost, possible negative effects for market liquidity and market efficiency are theoretically predicted but hardly empirically analyzed yet. In the light of the agreement of many European states to implement a STT, empirical evidences are further desirable especially within fragmented European market system. This study aims to give insights into this research gap and illustrates the market's reaction. Therefore, we give a comprehensive overview over the effects the STT has on market quality, i.e. trading activity, volatility, market liquidity and inter-market information transmission.

In line with the related literature (Baltagi et al., 2006; Pomeranets \& Weaver, 2012; Umlauf, 1993) we find trades deteriorating. However, the exact amount of the decline is hard to test, which is why we give a pure French as well as a benchmarked indication. Within 40 days after the adaption, we find trades within the French CAC 40 declining by about $16 \%$ compared to the benchmark, likewise declining by $21 \%$ within 10 days. Therefore the effect of the STT is peaking immediatly after the introduction of the STT. Trading volumes, although not persistent significant immediately, are declining by a sligthly smaller range of $7 \%$. A possible explanation for the difference in trades and volumes may be at least a partial adoption of participant's trade sizes. To avoid being taxed frequently, traders may increase trade sizes and therefore trade slightly lower volumes in significantly fewer trades. In line with $\mathrm{Hu}$ (1998) and Chou and Wang (2005) price volatility seems to be not affected by the STT, as improvements in standard deviation and high to low ratios are also observable within our benchmark group. However, not only liquidity demand is declining. By analyzing order book averages, we find spread as well as order book depth seriously deteriorating. Therefore, not only liquidity exploiting participants retreat from the order book as predicted in the theoretical literature (Palley, 1999). Instead, high-quality traders leveling spread and top order book depth leave the market leading to wider spreads as well as thinner order books within the upper and lower order book.

Most certainly, these results indicate that market participants are not only burdened by the tax itself, but additionally by an average $15 \%$ (benchmarked $12 \%$ ) wider relative spread as well as a thinner order book within 10 basis points around the midpoint (19\%, benchmarked 29\%). These results exemplarily indicate the traversing and amplifying effect on the implicit transaction costs due to a rise in the explicit transaction cost as argued by Habermeier and Kirilenko (2001). Higher explicit fees will impede and disperse liquidity provision further amplifying the increase in overall transaction costs. Most interesting, considering the various exemptions for professional liquidity provision, market liquidity could not be maintained by these market participants alone although spread and trade seem to recover over time.

Additionally, we find this dwindling spiral influencing the inter-market information transmission efficiency. A fragmented market system, like in Europe, is bound by information transmission between markets and liquidity sources through a constantly maintained and renewed price equilibrium like shown by F. d. Harris et al. (1995) and F. d. Harris et al. (2002). Price homogeneity within a fragmented market system de- 
termines market integrity and market efficiency. However, since the introduction of the French STT we find price coordination between NYSE Euronext Paris and Chi-X Europe significantly decreased. At first, average price difference has increased by $20 \%$ even though both venues are taxed equally. Therefore price inefficiencies between both markets are exploited less efficient by arbtrageurs as the price dipersion must further increase in order to become profitable again. Secondly, the equilibrium correction mechanism (reversion to the long-term price equilibrium) has been weakened persistently. Hence, one-sided information shocks last longer and consume additional time in order to be reversed. Within a system of fragmented liquidity such developements prevent a homogeneous price and therefore encourage fragmented pricing hampering investors to trade on fully incoperated information.

Our results show robustness among various market quality parameters. However, there are limitations which could not be addressed and also further questions remain. As the presented analysis relies on the comparison of the CAC40 against the German DAX 30 index, which is in most cases appropriate, a potential bias due the French instruments' idiosyncrasy could not be entirely ruled out. Regarding the success in dampening excessive order transmission activity induced by speculators further research activities are preferable. To establish more generalizability other trading venues and instruments need to be taken into account. Also important are macroeconomic effects like for instance long-term capital adjustment effects as proclaimed in theoretical as well as in some empirical studies, which we could not observe as of 2012. Foremost, Summers and Summers (1989) argue that the taxation of trades may free speculative capital allowing a redistribution among more sustainable investments. 


\section{References}

Amihud, Y. (2002). Illiquidity and stock returns: cross-section and time-series effects. Journal of Financial Markets, 5(1), 31-56.

Baltagi, B. H., Li, D., \& Li, Q. (2006). Transaction tax and stock market behavior: evidence from an emerging market. Empirical Economics, 31(2), 393-408.

Chou, R. K., \& Wang, G. H. K. (2005). Transaction tax and market quality of the taiwan stock index futures. Working Paper.

Culp, C. L. (2010). Financial transaction taxes: Benefits and cost. Working Paper.

Degryse, H., Jong, F. de, \& Kervel, V. van. (2011). Equity market fragmentation and liquidity: the impact of mifid. Working Paper.

Demary, M. (2011). Transaction taxes, greed and risk aversion in an agent-based financial market model. Journal of Economic Interaction and Coordination, 6(1), 1-28.

Dickey, D. A., \& Fuller, W. A. (1979). Distribution of the estimators for autoregressive time series with a unit root. Journal of the American Statistical Association, 74(366), 427-431.

Dupont, D. Y., \& Lee, G. S. (2007). Effects of securities transaction taxes on depth and bid-ask spread. Economic Theory, 31(2), 393-400.

Engle, R. F., \& Granger, C. W. J. (1987). Co-integration and error correction: Representation, estimation, and testing. Econometrica, 55(2), 251-76.

Fidessa. (2012). Fidessa Fragmentation Index. Retrieved January 07, 2013, from http://fragmentation.fidessa.com/.

French Government. (2013). French Tax Law. Retrieved January 14, 2013, from http://www.legifrance.gouv.fr/.

German High Frequency Trading Act. (2013). Diskussionsentwurf eines Gesetzes zur Vermeidung von Gefahren und Missbräuchen im Hochfrequenzhandel. Retrieved January 07, 2013, from http://www.bundesfinanzministerium.de.

Gomber, P., Arndt, B., Lutat, M., \& Uhle, T. (2011). High frequency trading. Working Paper.

Government Office for Science - Foresight. (2012). Order to trade ratios and their impact on Italian stock market quality. Retrieved January 07, 2013, from http://www.bis.gov.uk/assets/foresight/docs/computer-trading/12-1077-eia18-orderto-trade-ratios-impact-italian-stock-market.

Green, C. J., Maggioni, P., \& Murinde, V. (2000). Regulatory lessons for emerging stock markets from a century of evidence on transactions costs and share price volatility in the london stock exchange. Journal of Banking \& Finance, 24(4), 577-601.

Habermeier, K., \& Kirilenko, A. (2001). Securities transaction taxes and financial markets. IMF Working Papers, 01/51.

Hanke, M., Huber, J., Kirchler, M., \& Sutter, M. (2010). The economic consequences of a tobin tax - an experimental analysis. Journal of Economic Behavior 83 Organization, 74(1-2), 58-71.

Harris, F. d., McInish, T., Shoesmith, G., \& Wood, R. (1995). Cointegration, error correction and price discovery on informationally-linked security markets. Journal of Financial and Quantitative Analysis, 30, 563-579.

Harris, F. d., McInish, T., \& Wood, R. (2002). Security price adjustment across exchanges: an investigation of common factor components for dow stocks. Journal of Financial Markets, $5,277-308$.

Harris, L. (2003). Trading and exchanges: Market microstructure for practitioners. Oxford University Press.

Hasbrouck, J. (1995). One security, many markets: Determining the contributions to price discovery. Journal of Finance, 50(4), 1175-99.

Hau, H. (2006). The role of transaction costs for financial volatility: Evidence from the paris bourse. Journal of the European Economic Association, 4(4), 862-890.

Hendershott, T., \& Riordan, R. (2011). Algorithmic trading and information. Working Paper.

Holden, C. W. (2009). New low-frequency spread measures. Journal of Financial Markets, 12(4), 778-813. 
Hu, S.-Y. (1998). The effects of the stock transaction tax on the stock market - experiences from asian markets. Pacific-Basin Finance Journal, 6(3-4), 347-364.

Huang, R. D., \& Stoll, H. R. (1997). The components of the bid-ask spread: A general approach. Review of Financial Studies, 10(4), 995-1034.

Imbens, G., \& Wooldridge, J. (2007). Recent developments in the econometrics of program evaluation. Working Paper.

Jarrell, G. A. (1984). Change at the exchange: The causes and effects of deregulation. Journal of Law and Economics, 27(2), 273-312.

Jones, C. M., \& Seguin, P. J. (1997). Transaction costs and price volatility: Evidence from commission deregulation. The American Review, 87(4), 728-737.

Kupiec, P. H. (1996). Noise traders, excess volatility, and a securities transactions tax. Journal of Financial Services Research, 10(2), 115-129.

Lamont, O., \& Thaler, R. (2003). The law of one price in financial markets. The Journal of Economic Perspectives, 17, 191-202.

Lanne, M., \& Vesala, T. (2010). The effect of a transaction tax on exchange rate volatility. International Journal of Finance \& Economics, 15(2), 123-133.

Liu, S. (2007). Securities transaction tax and market efficiency: Evidence from the japanese experience. Journal of Financial Services Research, 32(3), 161-176.

Liu, S., \& Zhu, Z. (2009). Transaction costs and price volatility: New evidence from the tokyo stock exchange. Journal of Financial Services Research, 36 (1), 65-83.

Lutat, M. (2010). The effect of maker-taker pricing on market liquidity in electronic trading systems - empirical evidence from european equity trading. Working Paper.

Mannaro, K., Marchesi, M., \& Setzu, A. (2008). Using an artificial financial market for assessing the impact of tobin-like transaction taxes. Journal of Economic Behavior $\&$ Organization, $67(2), 445-462$.

Martinez, V. H., \& Rosu, I. (2011). High frequency traders, news and volatility. Working Paper.

Matheson, T. (2011). Taxing financial transactions: Issues and evidence. IMF Working Papers, $11 / 54$.

McCulloch, N., \& Pacillo, G. (2011). Security transaction taxes and market quality. IDS Research Reports(68).

Newey, W. K., \& West, K. D. (1987). A simple, positive semi-definite, heteroskedasticity and autocorrelation consistent covariance matrix. Econometrica, 55(3), 703-08.

Palley, T. I. (1999). Speculation and tobin taxes: Why sand in the wheels can increase economic efficiency. Journal of Economics, 69(2), 113-126.

Pellizzari, P., \& Westerhoff, F. (2009). Some effects of transaction taxes under different microstructures. Journal of Economic Behavior \& Organization, 72(3), 850-863.

Phylaktis, K., \& Aristidou, A. (2007). Security transaction taxes and financial volatility: Athens stock exchange. Applied Financial Economics, 17(18), 1455-1467.

Pollin, R., Baker, D., \& Schaberg, M. (2003). Securities transaction taxes for u.s. financial markets. Eastern Economic Journal, 29(4), 527-558.

Pomeranets, A., \& Weaver, D. (2012). Security transaction taxes and market quality. Working Paper.

PriceWaterhouseCoopers. (2012). French financial transaction tax on equity securities. Retrieved January 14, 2013, from http://www.pwc.be/en/financial-servicesnewsalert/2012/landwell-fftt-pdf-aug-2012.pdf.

Roll, R. (1989). Price volatility, international market links, and their implications for regulatory policies. Journal of Financial Services Research, 3(2-3), 211-246.

Saporta, V., \& Kan, K. (1997). The effects of stamp duty on the level and volatility of uk equity prices. Bank of England working papers, 71.

Schwert, W., \& Seguin, P. J. (1993). Securities transaction taxes: An overview of costs, benefits and unresolved questions. Financial Analysts Journal, 49(5), 27-35.

Sinha, P., \& Mathur, K. (2012). Securities transaction tax and the stock market - an indian experience. MPRA Paper, 42743.

Snow, J. (1855). On the mode of communication of cholera. John Churchill. 
Song, F. M., \& Zhang, J. (2005). Securities transaction tax and market volatility. The Economic Journal, 115(506), 1103-1120.

Spahn, P. B. (1995). International financial flows and transactions taxes: Survey and options. IMF Working Papers, 95/60.

Stiglitz, J. E. (1989). Using tax policy to curb speculative short-term trading. Journal of Financial Services Research, 3(2-3), 101-115.

Subrahmanyam, A. (1998). Transaction taxes and financial market equilibrium. The Journal of Business, 71(1), 81-118.

Summers, L. H., \& Summers, V. P. (1989). When financial markets work too well: A cautious case for a securities transactions tax. Journal of Financial Services Research, 3(2-3), 261-286.

Tobin, J. (1978). A proposal for international monetary reform. Eastern Economic Journal, 4 (3-4), 153-159.

Umlauf, S. R. (1993). Transaction taxes and the behavior of the swedish stock market. Journal of Financial Economics, 33(2), 227-240.

Wooldridge, J. M. (2002). Econometric analysis of cross section and panel data. Massachusetts London, England: The MIT Press Cambridge. 